Article

\title{
Simultaneous Adsorption of Cationic Dyes from Binary Solutions by Thiourea-Modified Poly(acrylonitrile-co-acrylic acid): Detailed Isotherm and Kinetic Studies
}

\author{
Abel Adekanmi Adeyi ${ }^{1,2} \mathbb{D}^{\text {, Siti Nurul Ain Md Jamil }}{ }^{3,4 * * \mathbb{D}}$, Luqman Chuah Abdullah 1,5(D), \\ Thomas Shean Yaw Choong ${ }^{1,5}$, Kia Li Lau ${ }^{1}$ and Mohammad Abdullah ${ }^{6}$ \\ 1 Department of Chemical and Environmental Engineering, Faculty of Engineering, Universiti Putra Malaysia, \\ UPM Serdang 43400, Malaysia; abeladeyi@abuad.edu.ng (A.A.A.); chuah@upm.edu.my (L.C.A.); \\ csthomas@upm.edu.my (T.S.Y.C.); laukiali@hotmail.com (K.L.L.) \\ 2 Department of Chemical and Petroleum Engineering, College of Engineering, Afe Babalola University \\ Ado-Ekiti, ABUAD, KM. 8.5, Afe Babalola Way, PMB 5454, Ado-Ekiti, Ekiti State 360211, Nigeria \\ 3 Department of Chemistry, Faculty of Science, Universiti Putra Malaysia, UPM Serdang 43400, Malaysia \\ 4 Centre of Foundation Studies for Agricultural Science, Universiti Putra Malaysia, \\ UPM Serdang 43400, Malaysia \\ 5 Institute of Tropical Forestry and Forest Products (INTROP), Universiti Putra Malaysia, \\ UPM Serdang 43400, Malaysia \\ 6 Faculty of Chemical Engineering, Universiti Teknologi Mara, 81750 Masai, Johor Darul Takzim, Malaysia; \\ moham3767@johor.uitm.edu.my \\ * Correspondence: ctnurulain@upm.edu.my; Tel.: +60-12-356-6076
}

Received: 23 June 2019; Accepted: 22 July 2019; Published: 8 September 2019

check for updates

\begin{abstract}
In this study, simultaneous adsorption of cationic dyes was investigated by using binary component solutions. Thiourea-modified poly(acrylonitrile-co-acrylic acid) (TMPAA) polymer was used as an adsorbent for uptake of cationic dyes (malachite green, MG and methylene blue, MB) from aqueous solution in a binary system. Adsorption tests revealed that TMPAA presented high adsorption of $\mathrm{MG}$ and $\mathrm{MB}$ at higher $\mathrm{pH}$ and higher dye concentrations. It suggested that there are strong electrostatic attractions between the surface functional groups of the adsorbent and cationic dyes. The equilibrium analyses explain that both extended Langmuir and extended models are suitable for the description of adsorption data in the binary system. An antagonistic effect was found, probably due to triangular (MG) and linear (MB) molecular structures that mutually hinder the adsorption of both dyes on TMPAA. Besides, the kinetic studies for sorption of MG and MB dyes onto adsorbent were better represented by a pseudo-second-order model, which demonstrates chemisorption between the polymeric TMPAA adsorbent and dye molecules. According to experimental findings, TMPAA is an attractive adsorbent for treatment of wastewater containing multiple cationic dyes.
\end{abstract}

Keywords: adsorption; poly(acrylonitrile-co-acrylic acid); thiourea; cationic dyes; binary system; isotherms; kinetics

\section{Introduction}

Rapid growth in population and industrial activities have ensued in accumulation of pollutants in the environment due to their waste disposal without any treatment [1,2]. It is reported that about 1.2 trillion tons of non-treated industrial wastewater and storm water are discharged into the environment per annum [3,4]. Industries such as paint, textile, paper, rubber, leather, petroleum, pharmaceutical, and food are major contributors, enhancing the concentration of contaminant present 
in wastewater [5-8]. Over 100,000 synthetic dyes-cationic, anionic and dispersive-have been broadly used in the aforementioned industries generating volumes of wastewater annually. They are by design highly stable molecules not easy to biodegrade, made to resist degradation by chemical, biological, and light exposure, as well as their multifarious chemical structure [9]. These pose a big challenge and are harmful to ecological and environmental systems-reducing light penetration and photosynthesis $[10,11]$. Under anaerobic conditions, some cationic dye-bearing wastewater breaks down into hazardous aromatic amines, causing critical health problems to animals and humans [12]. Treatment of industrial wastewater especially dye bearing wastewater in order to meet stringent discharge regulations in industrial operations is a major concern globally.

Various developed technologies are available for isolation of dye ions present in wastewater such as anaerobic decomposition, membrane separation, precipitation, electrocoagulation, and flocculation. Photo-oxidation and biological degradation has also been proposed and cited for the treatment of color containing effluents. Conversely, this method is relatively expensive and complex. Alternatively, adsorption remains the most common and efficient decontamination technology for dye bearing industrial effluents [13-15]. Many researches have been made on the possibility of adsorbents using mineral sorbents, activated carbon, peat, chitin, rice husk, soy meal hull, and other agricultural wastes. The sorption capacity of these adsorbents is not very effective to improve adsorption performance [16]. Preparation of new polymer-based adsorbents with functional groups that have significant effects on the efficiency, selectivity, and reusability is of utmost concern for researchers, due to the germane role of the adsorbent in adsorption technique. Several chelating resins have been prepared through grafting of monomers onto natural or synthetic polymer matrix and conventional polymerization of the monomers such as acrylonitrile (AN), acrylic acid (AA), methacrylic acid (MA), and divinylbenzene (DVB-80) [17]. Furthermore, chemical modification of a synthesized polymer milieu by a chelating moiety such as amine, thiourea, and amino-acids has also been used to produce new/modified polymeric adsorbents $[15,16,18,19]$. In such studies, the carboxyl and amine groups have been established to be two most effective functional groups for removal of organic and inorganic pollutants from aqueous solutions.

Moreover, previous researches on dye adsorption were carried out explicitly in single dye systems and scanty study reports were available in binary dye systems. Our previous work reports in detail preparation and characterization of thiourea-modified poly(acrylonitrile-co-acrylic acid) (TMPAA) and its adsorption capacities towards MG and MB in a single dye system [20-22]. Generally, multiple components of dyes coexist in real industrial wastewater systems. This multiplicity in actual applications may affect the dye adsorption process either in antagonistic or synergistic manner [23,24]. Therefore, it is imperative to investigate adsorption of dye both in single and multiple dye systems. Herein, this study aims to assess TMPAA applicability for the adsorptive removal of cationic dyes from aqueous solution in binary systems. Binary adsorption isotherms and kinetics of MG and MB uptake by TMPAA polymer were also investigated.

\section{Materials and Methods}

\subsection{Chemicals and Reagents}

All chemical reagents purchased were analytical grade, used without further purification except acrylonitrile (AN) and acrylic acid (AA) (Acros Organics, Morris, NJ, USA) purified by aluminium oxide (Merck, Darmstadt, Germany) with glass wool. Potassium persulphate (KPS) and sodium bisulphate (SBS) (R\&M Chemicals, Essex, UK) were used as initiators for free radical polymerization. Methanol and ethanol were purchased from Systerm ChemAR (Shah Alam, Malaysia). Thiourea (R\&M Chemicals, Essex, UK) was used to modify the synthesized copolymer. Hydrochloric acid and sodium hydroxide (R\&M Chemicals, Essex, UK) were used for the pH adjustment. The two cationic dyes, malachite green (MG) and methylene blue (MB) purchased from Acros Organics, NJ, USA, were used as adsorbate. Their general properties and structures are shown in Table 1 and Figure 1, respectively. 


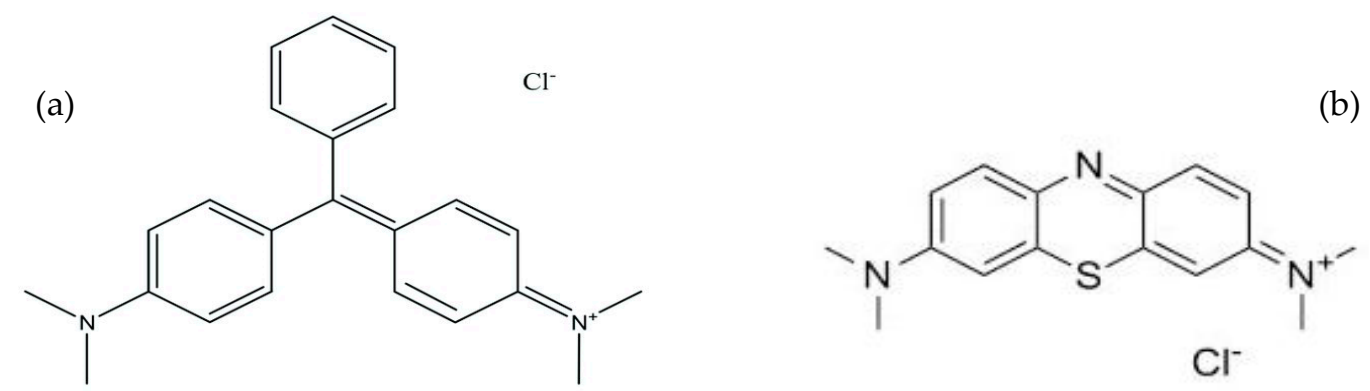

Figure 1. Molecular structures of (a) malachite green and (b) methylene blue.

Table 1. General properties of cationic MG and MB dyes.

\begin{tabular}{ccc}
\hline Name of the Commercial Dye & Malachite Green, MG & Methylene Blue, MB \\
\hline Colour Index Name & Basic Green 4 & Basic Blue 9 \\
$\lambda$ max $(\mathrm{nm})$ & 617 & 665 \\
Molecular Weight $(\mathrm{g} / \mathrm{mol})$ & 364.92 & 319.85 \\
Charge & $(+)$ & $(+)$ \\
Chemical Formula & $\mathrm{C}_{23} \mathrm{H}_{25} \mathrm{ClN}_{2}$ & $\mathrm{C}_{16} \mathrm{H}_{18} \mathrm{ClN}_{3} \mathrm{~S}$ \\
\hline
\end{tabular}

\subsection{Preparation of Thiourea-Modified Poly(acrylonitrile-co-acrylic acid)(TMPAA)}

Poly(acrylonitrile-co-acrylic acid) was synthesized and modified according to previous work [21]. The feed ratio of monomers AN:AA was 97:3 (vol/vol). The reaction medium, $200 \mathrm{~mL}$ deionized water was initially purged with $\mathrm{N}_{2}$ gas for $30 \mathrm{~min}$ at $40^{\circ} \mathrm{C}$. Then, $\mathrm{AN}$ and AA were introduced into the reaction medium followed by KPS and SBS (as initiator). The solution was stirred mechanically at $200 \mathrm{rpm}$, and the reaction was allowed for $120 \mathrm{~min}$. The produced copolymer (poly(AN-co-AA)) was soaked in methanol, filtered, and washed successively with methanol and deionized water. The copolymer was oven dried at $45^{\circ} \mathrm{C}$ until a constant mass white powder.

For surface functionalization, $6.0 \mathrm{~g}$ of thiourea and ethanol/deionized water (1:2\% volume) were mixed and stirred continuously at $200 \mathrm{rpm}$ for $0.5 \mathrm{~h}$ at $70^{\circ} \mathrm{C}$. Then, $5.0 \mathrm{~g}$ of poly(AN-co-AA) was added to the solution for $5 \mathrm{~h}$ at $100^{\circ} \mathrm{C}$. Then, the resulting solids, thiourea-modified poly(AN-co-AA) (TMPAA), rinsed liberally in ethanol/deionized water solution, filtered, and dried at $50{ }^{\circ} \mathrm{C}$ to constant mass.

\subsection{Binary Adsorption Studies}

Adsorptive tests of MG and MB cationic dyes on TMPAA in binary systems were performed in a batch mode. $100 \mathrm{~mL}$ solutions of dyes ( $50 \mathrm{~mL}$ of MG and $50 \mathrm{~mL}$ of MB) were prepared with one dye at a fixed concentration and the other at varying concentrations. One set of tests were performed at fixed $\mathrm{MB}$ concentration of $20 \mathrm{mg} / \mathrm{L}$ and second set at $100 \mathrm{mg} / \mathrm{L}$ of MB, while various MG concentrations at 20-100 mg/L. Under constant stirring speed of $100 \mathrm{rpm}$, the solutions were controlled at $25^{\circ} \mathrm{C}$, and $100 \mathrm{rpm}$ agitation speed. The other set of experiments was carried out at constant MG concentrations (20 and $100 \mathrm{mg} / \mathrm{L}$ ) while MB was varied from 20 to $100 \mathrm{mg} / \mathrm{L}$. TMPAA at $0.5 \mathrm{~g}$ was mixed with the dye solutions and kept at $100 \mathrm{rpm}, 25^{\circ} \mathrm{C}$. The solutions were withdrawn at several time intervals, filtered for dye concentration measurement. The absorbance was measured at two wavelengths of 617 and $665 \mathrm{~nm}$ by a Lambda $35 \mathrm{UV}$-Vis spectrophotometer. The following equations were used to determine the dye concentrations $[25,26]$.

$$
\begin{aligned}
& C_{M G}=\frac{\left(K_{M B 2} A_{1}\right)-\left(K_{M B 1} A_{2}\right)}{\left(K_{M G 1} K_{M B 2}\right)-\left(K_{M G 2} K_{M B 1}\right)} \\
& C_{M B}=\frac{\left(K_{M G 1} A_{2}\right)-\left(K_{M G 2} A_{1}\right)}{\left(K_{M G 1} K_{M B 2}\right)-\left(K_{M G 2} K_{M B 1}\right)}
\end{aligned}
$$


Where $K_{M G 1}$ and $K_{M B 1}$ represent the calibration constants for dyes MG and MB at $\lambda_{1, \max }$ while $K_{M G 2}$ and $K_{M B 2}$ represent the calibration constants for dyes MG and MB at $\lambda_{2, \max } . A_{1}$ and $A_{2}$ are the absorbance at wavelength $\lambda_{1, \max }$ and $\lambda_{2, \max }$, respectively.

The calculation of the extent of dye uptake, $R(\%)$, and adsorbent sorption capacity at equilibrium $\left(q_{e}\right)$ condition can be expressed as:

$$
\begin{gathered}
\% R=\frac{C_{o}-C_{e}}{C_{o}} \times 100 \\
q_{e}=V \frac{C_{o}-C_{e}}{m_{a d s}}
\end{gathered}
$$

$C_{o}(\mathrm{mg} / \mathrm{L})$ and $C_{e}(\mathrm{mg} / \mathrm{L})$ are the concentrations of the cationic dye at initial and equilibrium respectively; $q_{e}(\mathrm{mg} / \mathrm{g})$ is the amount of dye adsorbed, $V(\mathrm{~L})$ is the volume of the dye solution and $m_{a d s}$ (g) the weight of the TMPAA adsorbent used. All the experimental tests were performed thrice and the average value recorded.

\subsection{Calculation of Adsorption Isotherms}

The single adsorption isotherms were calculated using the Langmuir and Freundlich models. The Langmuir isotherm and Freundlich isotherm equations can be expressed linearly and respectively as [27-29]:

$$
\begin{aligned}
\frac{C_{e}}{q_{e}} & =\frac{1}{K_{L} q_{\max }}+\frac{C_{e}}{q_{\max }} \\
\ln \left(q_{e}\right) & =\ln \left(K_{F}\right)+\frac{1}{n} \ln \left(C_{e}\right)
\end{aligned}
$$

$q_{\max }(\mathrm{mg} / \mathrm{g})$ is the Langmuir maximum adsorption capacity. $K_{L}$ and $K_{F}$ represent respectively Langmuir and Freundlich constants, and the heterogeneity factor is denoted by $n$.

The single component isotherm equations are extended and/or modified to investigate the interactions between the adsorption capacity of a component and the concentration of other components present in wastewater. The extended Langmuir model (also known as non-modified competitive Langmuir isotherm) for binary systems can be written as [30]

$$
\begin{aligned}
q_{e, 1} & =\frac{q_{\max , 1} K_{L, 1} C_{e, 1}}{1+K_{L, 1} C_{e .1}+K_{L, 2} C_{e, 2}} \\
q_{e, 2} & =\frac{q_{\max , 2} K_{L, 2} C_{e, 2}}{1+K_{L, 1} C_{e .1}+K_{L, 2} C_{e, 2}}
\end{aligned}
$$

The parameters $q_{\max , 1}, K_{L, 1}$, and $K_{L, 2}$ were evaluated for a series of experimental values of $q_{e, 1}$ and $C_{e, 1}$ by minimizing the error in non-linear regression analysis or applying solver function of non-linear regression in Microsoft Excel [31].

The extended Freundlich model is applied to multilayer heterogeneous adsorption systems when the interaction is occurring among the adsorbed components [31,32]. The extended Freundlich equation for a binary system is expressed as

$$
\begin{array}{r}
q_{e, 1}=\frac{K_{F, 1} C_{e, 1}^{\left(\frac{1}{n_{1}}\right)+x_{1}}}{C_{e, 1}^{x_{1}}+y_{1} C_{e, 2}^{z_{1}}} \\
q_{e, 2}=\frac{K_{F, 2} C_{e, 2}^{\left(\frac{1}{n_{2}}\right)+x_{2}}}{C_{e, 2}^{x_{2}}+y_{2} C_{e, 1}^{z_{2}}}
\end{array}
$$

$q_{e, 1}$ and $q_{e, 2}$ are the equilibrium adsorption capacity for solute 1 and $2(\mathrm{mg} / \mathrm{g})$, respectively. $C_{e, 1}$ and $C_{e, 2}$ represent the equilibrium concentration of component 1 and $2(\mathrm{mg} / \mathrm{L})$, respectively. The values of adsorption intensities $n_{1}, n_{2}$ and Freundlich constant $K_{F, 1}$ and $K_{F, 2}$ are obtained from the experimental 
data of individual Freundlich models. The values of constants $x_{1}, y_{1}, z_{1}$ and $x_{2}, y_{2}, z_{2}$ were obtained by minimizing error in non-linear regression analysis for a series of experimental values of $q_{e, 1}$ versus $C_{e, 1}$ and $q_{e, 2}$ versus $C_{e, 2}$ respectively [30,33].

\subsection{Competition and Interaction Mechanism}

Three distinct forms of interactions are feasible between the adsorbate molecules in a multicomponent adsorption system. Interaction effects are described based on the ratio of adsorption capacity of an adsorbent $\left(Q_{m}\right)$ in a multicomponent solution to the sorption capacity of contaminant $\left(Q_{i}\right)$ in a single component solution. The possible interactions among the adsorbate molecules are:

(a) Antagonistic interaction: This occurred when the adsorption capacity of an adsorbent reduces in a solution containing other components $\left(Q_{m} / Q_{i}<1\right)$.

(b) Synergistic interaction: The adsorption capacity of an adsorbent increases when it is in association with other components $\left(Q_{m} / Q_{i}>1\right)$.

(c) Non-interaction: The adsorption capacity is independent of the absence or presence of other components in a solution $\left(Q_{m} / Q_{i}=1\right)[34,35]$.

Several principles and methods are employed to explain the interaction between the species in a binary adsorption system. These terms further describe how a component inhibits the adsorption of other components in the multi-component solution.

P-Factor: The P-factor model is a correlative technique developed by McKay and Al Duri (1987) and used to compare the monocomponent isotherm data with the binary isotherm data. The P-factor $\left(P_{f i}\right)$ elucidates how the adsorption of a component is inhibited by other components in a binary mixture. It is given as:

$$
P_{f i}=\frac{Q_{i, s}}{Q_{i, b}}
$$

$Q_{i, s}$ and $Q_{i, b}$ represent the sorbent capacity for the component $i$ in the single component solution and the binary system. $P_{f i}$ value defined the nature of the interaction (inhibition, enhancement, or non-interference) between the two components. The value of $P_{f i}=1$ signifies unhindered interaction, $P_{f i}>1$ demonstrates that the adsorption of component $i$ is inhibited in the presence of other solutes, while adsorption of component $i$ enhanced at $P_{f i}<1$ [36-38].

Inhibitory Effect: In a multicomponent adsorption system, entrapment of an adsorbate may be influenced by another and is delineated by inhibitory effect $(\triangle I E)$ given as

$$
\Delta I E=\frac{Q_{i, s}-Q_{i, b}}{Q_{i, s}}
$$

The greater value of $\triangle I E$ indicates the suppression level of adsorption of one solute in the presence of another $[37,39,40]$.

Selectivity Ratio: The affinity of an adsorbent towards a particular component in a binary system is indicated by selectivity ratio $\left(S_{(i / j)}\right)$. Based on the morphology, surface structure, and pore distribution of an adsorbent, selectivity ratio investigates the adsorbent preference towards one solute in the presence of another [40-42]. The selectivity ratio is defined as

$$
S_{(i / j)}=\frac{Q_{i, b}}{Q_{j, b}}=\frac{Q_{i, s}}{Q_{j, s}}
$$

Where $Q_{i, b}$ and $Q_{i, s}$ represent the adsorption capacity of the component $i$ in the binary and single component solution. The value of $S_{(i / j)}$ being less than one implies that the adsorbent has more affinity towards component $j$ than the component $i$ [37]. 


\subsection{Calculation of Adsorption Kinetics}

In order to comprehend the nature and process of adsorption, pseudo-first-order and pseudo-second-order kinetic models were employed. The integral linear form of the Lagergren pseudo-first-order and Ho pseudo-second-order models can be expressed as: $[43,44]$

$$
\begin{gathered}
\ln \left(q_{e}-q_{t}\right)=\ln \left(q_{e}\right)-k_{1} t \\
\frac{t}{q_{t}}=\frac{1}{k_{2} q_{e}^{2}}+\frac{1}{q_{e}} t
\end{gathered}
$$

$q_{e}(\mathrm{mg} / \mathrm{g}), q_{t}(\mathrm{mg} / \mathrm{g})$ are respectively represent adsorption capacity at equilibrium and at time $t . k_{1}\left(\mathrm{~min} \cdot{ }^{-1}\right)$, and $k_{2}(\mathrm{~g} / \mathrm{mg} \mathrm{min}$.) are the rate constants for pseudo first-order and pseudo-second-order, respectively.

\section{Results and Discussions}

\subsection{Characterization of TMPAA}

Detail of the physical and chemical properties of TMPAA has been reported previously [21]. Presence of functional groups, $\mathrm{OH}$ and $\mathrm{NH}_{2}\left(3345 \mathrm{~cm}^{-1}\right),-\mathrm{C}-\mathrm{H}\left(2935 \mathrm{~cm}^{-1}\right),-\mathrm{C}=\mathrm{O}\left(1728 \mathrm{~cm}^{-1}\right)$, and $-\mathrm{C}=\mathrm{S}$ $\left(729 \mathrm{~cm}^{-1}\right)$, was revealed by FTIR spectrum. TMPAA was spherical with rough surface area as observed by SEM image. The adsorption isotherm of $\mathrm{N}_{2} / 77 \mathrm{~K}$ of the modified polymer corresponds to type IV and displayed the existence of narrow hysteresis loop. Mesoporous features of the TMPAA were confirmed by its BET surface area and pore size of $26.31 \mathrm{~m}^{2} / \mathrm{g}$ and $47.93 \mathrm{~nm}$, respectively. The surface charge measurement was negative in both acidic and alkaline media.

\subsection{Effect of Initial Dye Concentration and $p H$}

Figure 2 shows the influence of different initial MG dye concentrations on the extent (\%) of removal of MG by TMPAA while keeping the concentration of MB at $20 \mathrm{mg} / \mathrm{L}$ (Figure 2a) and $100 \mathrm{mg} / \mathrm{L}$ (Figure 2b), respectively. Simultaneously, the effect of the solution $\mathrm{pH}$ was investigated by adjusting the adsorption systems to $\mathrm{pH} 3,5$, and 9, respectively. The MG uptake was increased from $73.36 \%$ to $88.92 \%$ (pH 3), $74.98 \%$ to $90.74 \%(\mathrm{pH} 5)$ and $79.86 \%$ to $91.66 \%$ as the initial MG concentration was increased from $20 \mathrm{mg} / \mathrm{L}$ to $100 \mathrm{mg} / \mathrm{L}$ in the presence of $20 \mathrm{mg} / \mathrm{L} \mathrm{MB}$ dye. At higher MB concentration (100 mg/L), the MG uptake was raised from $75.69 \%$ to $86.49 \%$ (pH 3), while $80.43 \%-89.99 \%$ removal increment was observed at $\mathrm{pH} 9$.

As seen in Figure 2, the extent of MG dye uptake in a binary cationic dye solution improved with increasing concentration. It is due to enhancement in driving potency (induced by concentration gradient) required to subdue the resistance related to mass transfer between adsorbate and TMPAA adsorbent. Zhou and co-worker (2019) also report similar result trend for adsorption of rhodamine B (RhB), neutral red (NR), and MB cationic dyes onto sulfonated poly(arylene ether nitrile) (SPEN) based adsorbents [45]. Moreover, Figure 1 depicts that the extent of MB uptake was almost constant although the initial MG concentrations were increased from $20 \mathrm{mg} / \mathrm{L}$.

Figure 3 shows the impact of different initial MB dye concentrations on the extent (\%) MB uptake by TMPAA while keeping the concentration of MG at $20 \mathrm{mg} / \mathrm{L}$ (Figure 3a) and $100 \mathrm{mg} / \mathrm{L}$ (Figure 3b), respectively. The $\mathrm{pH}$ of the binary mixture was adjusted to 3,5 , and 9 to study the effect of $\mathrm{pH}$ on the extent of dye uptake by TMPAA adsorbent. The percentage MB removal (Figure 3a) was increased from $82.39 \%$ to $90.74 \%$ (pH 3), $84.78 \%$ to $91.10 \%(\mathrm{pH}$ ) and $85.52 \%$ to $93.99 \%(\mathrm{pH} 9$ ) as the initial MB concentration were raised from $20 \mathrm{mg} / \mathrm{L}$ to $100 \mathrm{mg} / \mathrm{L}$ in the presence of $20 \mathrm{mg} / \mathrm{L} \mathrm{MG}$ dye. At higher MG concentration (100 mg/L, Figure $3 b)$, the MB uptake was raised from $81.62 \%$ to $90.92 \%(\mathrm{pH} 3)$, $82.04 \%$ to $92.23 \%$ ( $\mathrm{pH}$ ) while $83.41 \%$ to $93.65 \%$ uptake increment was recorded at $\mathrm{pH} 9$. 

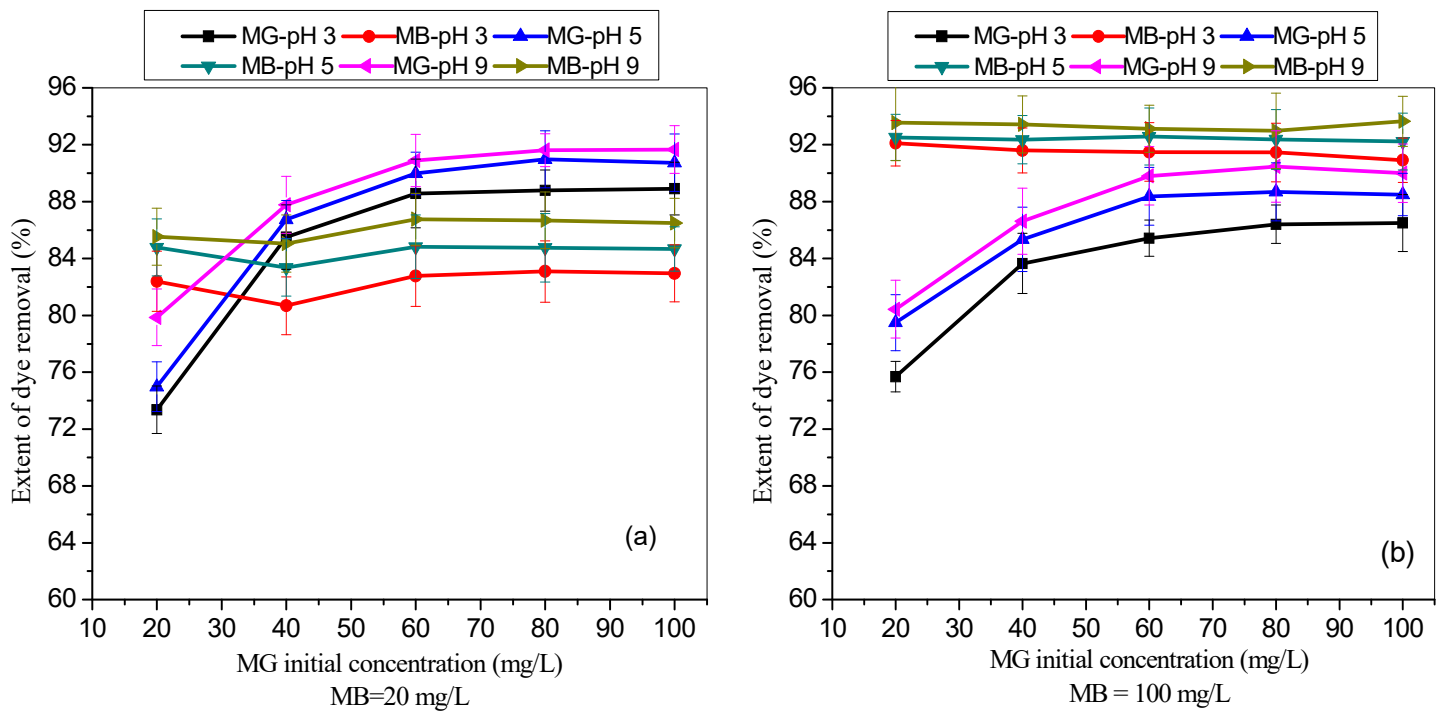

Figure 2. Effect of initial MG dye concentrations on the extent (\%) of dye uptake by TMPAA at different $\mathrm{pH}$ in the presence of (a) $20 \mathrm{mg} / \mathrm{L}$, and (b) $100 \mathrm{mg} / \mathrm{L}$ of MB (dose: $0.5 \mathrm{~g} / 100 \mathrm{~mL}$; agitation speed: $100 \mathrm{rpm}$; time: 2 hr.; temperature: $25^{\circ} \mathrm{C}$ ).
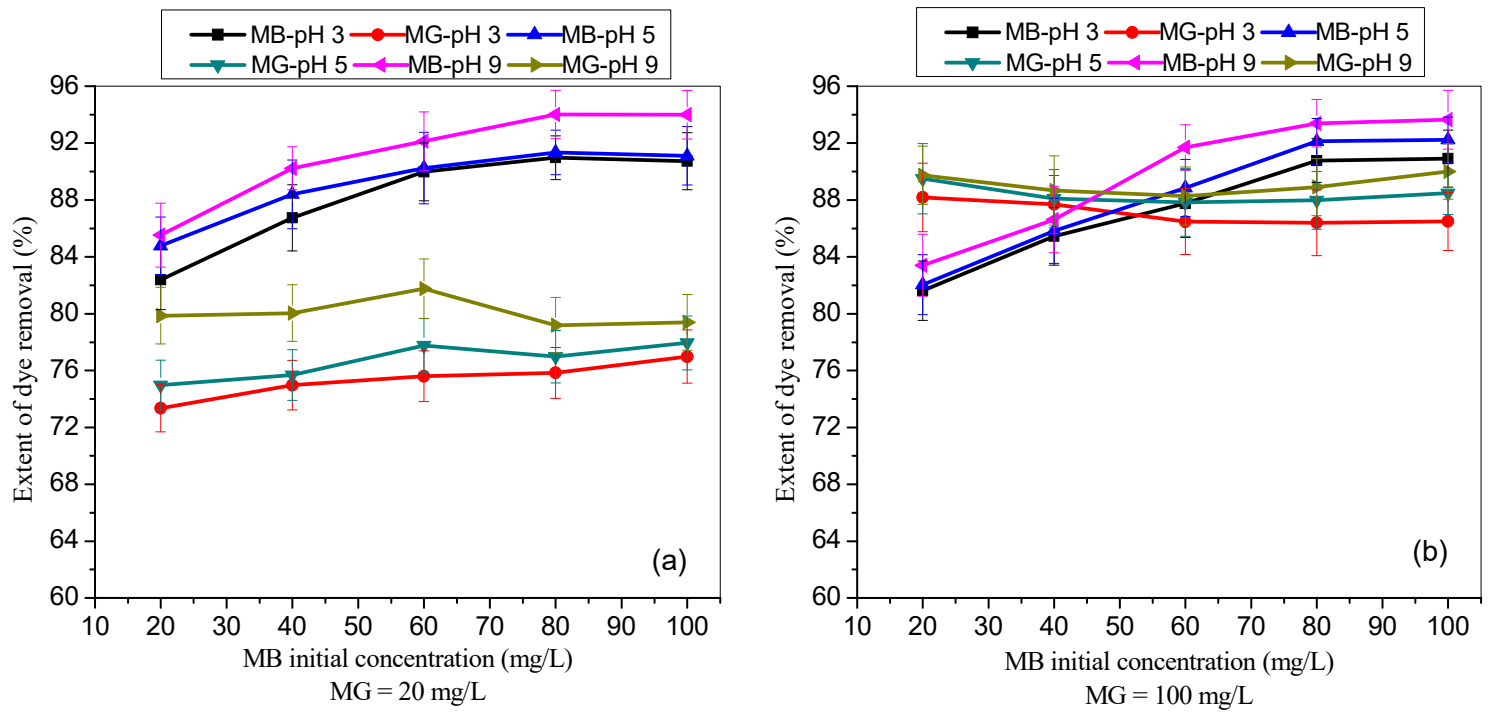

Figure 3. Effect of initial MB dye concentrations on the extent (\%) of dye uptake by TMPAA at different $\mathrm{pH}$ in the presence of (a) $20 \mathrm{mg} / \mathrm{L}$ and (b) $100 \mathrm{mg} / \mathrm{L}$ of MG (dose: $0.5 \mathrm{~g} / 100 \mathrm{~mL}$; agitation speed: $100 \mathrm{rpm}$; time: 2 hr.; temperature: $25^{\circ} \mathrm{C}$ ).

Remarkably, the extent of MG and MB dye removal in the binary system increased with increasing solution $\mathrm{pH}$ (Figures 2 and 3). This result is attributed to ionization of cationic dyes and TMPAA surface charge deprotonation [46]. The presence of thioamide groups on the polymeric adsorbent surface fully deprotonated in alkaline medium and negative charges was prompted in the polymer linkage. This negatively charged surface facilitates high sorption of positively charged cationic dyes from liquid phase due to an enhanced electrostatic pull. The low extent of dye uptake was observed in acidic condition due to protonation and increased the hydrophobicity of TMPAA microsphere. There was presence of additional positive charge at low $\mathrm{pH}$, which reduced the uptake of cationic MG and MB dyes due to repulsive force coupled with TMPAA preferential adsorption of excess $\mathrm{H}^{+}$ion compared to dye due to the smaller size. Similar adsorptive behaviour was reported by [47], indicating that adsorption of cationic dyes by poly( $N$-isopropylmethacrylamide-acrylic acid) microgels increased as the solution $\mathrm{pH}$ increases. 
Generally, TMPAA adsorbents exhibit slightly higher adsorption preference towards MB dye compared to MG dye in a binary system (Figure 4), probably due to their triangular (MG) and linear (MB) molecular structures. The adsorption capacity of TMPAA towards both dyes increased as the initial concentration increases. This is due to higher driving force propelled by a concentration gradient that overcomes mass transfer resistance between the adsorbent surface and dye solution.

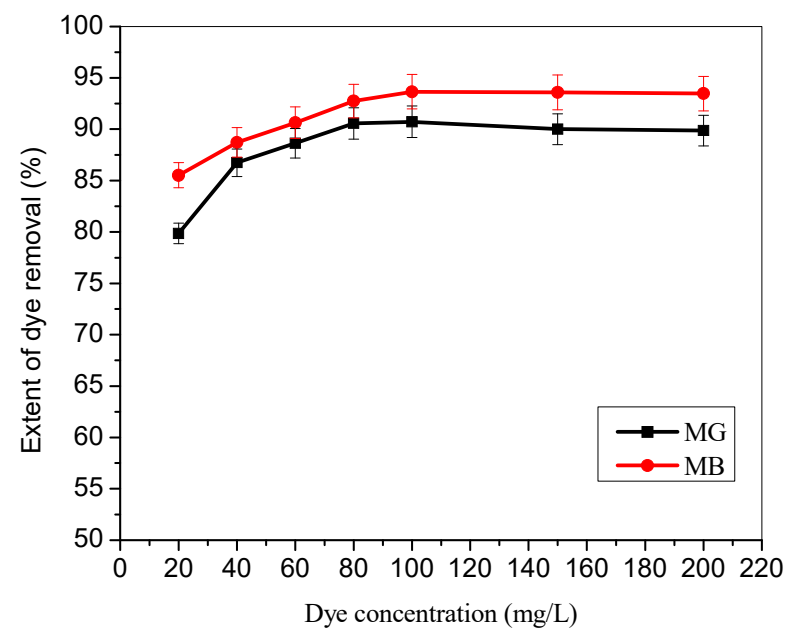

Figure 4. Effect of equal initial MG and MB dyes concentration on the extent of removal in a binary system (dose: $0.5 \mathrm{~g} / 100 \mathrm{~mL}$; agitation speed: $100 \mathrm{rpm}$; time: $2 \mathrm{hr}$.; temperature: $25^{\circ} \mathrm{C}$ ).

\subsection{Effect of TMPAA Dose}

The mass of adsorbent is a key parameter with a vital role in the adsorption process. To determine the optimum dosage of TMPAA, the polymeric adsorbent dose was varied from $0.3 \mathrm{~g}$ to $1.2 \mathrm{~g} / 100 \mathrm{~mL}$ of binary MG and MB mixture, continuously stirred for $1 \mathrm{hr}$ at room temperature. Figure $5 \mathrm{a}, \mathrm{b}$ shows the extent of MG and MB in a binary system. The extent of dye uptake in both cases was first increased rapidly up to $0.5 \mathrm{~g}$ TMPAA dose, then became almost constant. This sudden increment was due to an increase in adsorptive surface area as well as the availability of more binding sites for MG and MB dyes adsorption [47]. The percentage of MG and MB uptake increased as initial concentration increases (Figure 5). Further increment in the concentration of TMPAA particles portrayed little or non-significant increase in the cationic dye entrapment. This phenomenon may be associated with the availability of less dye adsorbate to be adsorbed compared to excess available active binding sites of TMPAA.

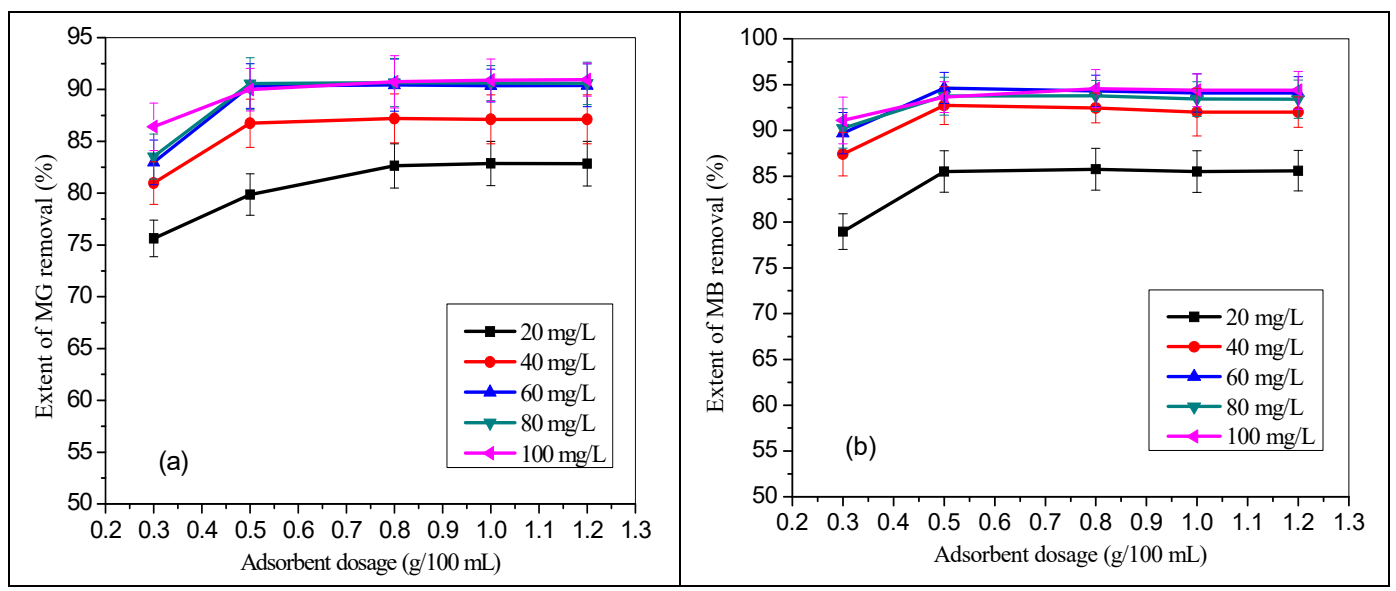

Figure 5. Effect of TMPAA dosage on the extent of dye uptake in a binary system (a) MG and (b) MB dyes (MG conc. $=$ MB conc.; agitation speed: $100 \mathrm{rpm}$; time: $2 \mathrm{hr}$; temperature: $25^{\circ} \mathrm{C}$ ). 


\subsection{Effect of Contact Time}

Determination of optimum contact or agitation time was performed at the varied initial concentration $(20-100 \mathrm{mg} / \mathrm{L})$ in a binary system. The results of optimum contact time for MG and MB uptake using TMPAA are presented in Figures 6 and 7, respectively. The influence of residence time (0-120 $\mathrm{min})$ on the extent of cationic dye uptake by TMPAA was investigated at $\mathrm{pH} 9,0.5 \mathrm{~g}$ TMPAA dose and at $25^{\circ} \mathrm{C}$.

Initially, the removal percentage of MG was rapid in the first $30 \mathrm{~min}$ and then attained equilibrium after $60 \mathrm{~min}$ of agitation time. Equilibrium in the adsorption process achieved after $1 \mathrm{~h}$ due to saturation of active binding sites. A similar phenomenon was observed in the case of MB uptake in the presence of MG dye. Increase in MG and MB concentration resulted in a rise in the quantity of dyes entrapped. This is attributed to the fact that adsorption was directly proportional to more concentration gradient at the initial stage, where migration and convection led to greater mass transfer from the bulk solution to TMPAA surface and its reactive binding sites. This result trend is in agreement with the findings of Mishra et al. (2017); Alqadami et al. (2018); Asfaram et al. (2017) and Idan et al., (2017) who also worked on adsorption of dyes [48-51].

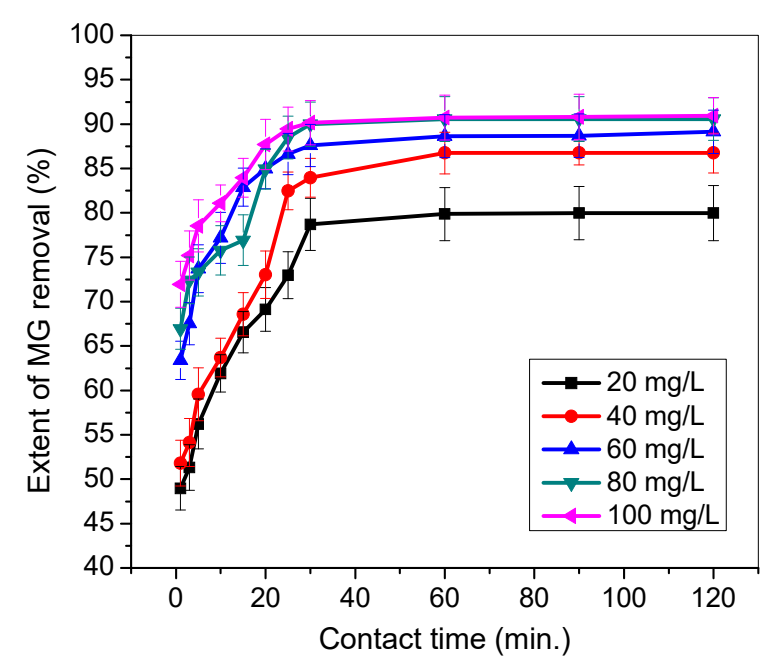

Figure 6. Effect of contact time on the adsorption of MG dyes in the presence of MB (temperature: $25^{\circ} \mathrm{C}$; agitation speed: $100 \mathrm{rpm}$; dosage: $0.5 \mathrm{~g} / 100 \mathrm{~mL}$; Conc. MG equal Conc. MB).

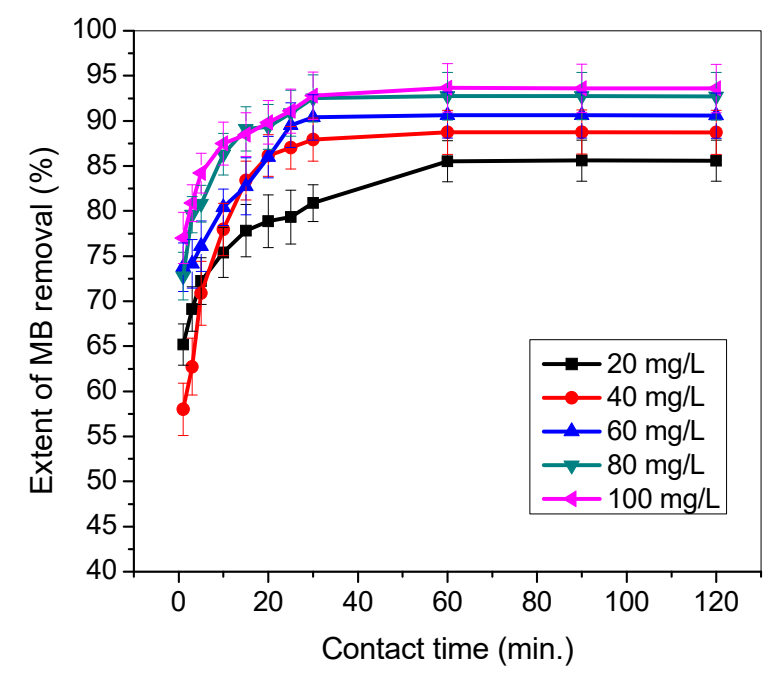

Figure 7. Effect of contact time on the adsorption of MB dyes in the presence of MG (temperature: $25{ }^{\circ} \mathrm{C}$; agitation speed: $100 \mathrm{rpm}$; dosage: $0.5 \mathrm{~g} / 100 \mathrm{~mL}$; Conc. MG equal Conc. MB). 
The extent of dye uptake as a function of time for the two cationic dye was compared and illustrated in Figure 8 in a binary system. TMPAA demonstrates higher preference towards adsorption of MB than MG. Then both dyes attained equilibrium almost at the same residence time.

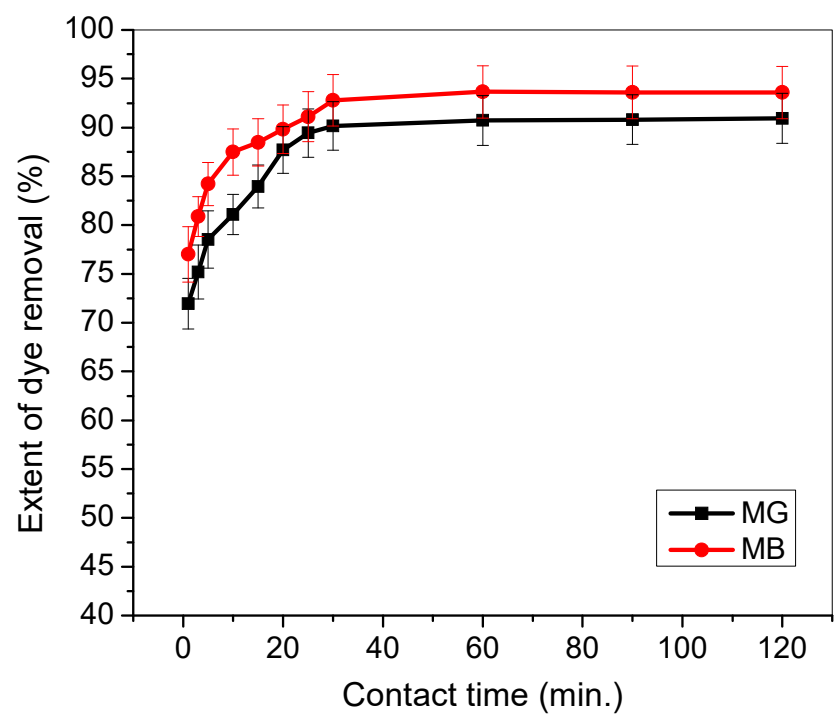

Figure 8. Effect of contact time on the adsorption of MG and MB dyes in a binary system (temperature: $25^{\circ} \mathrm{C}$; agitation speed: $100 \mathrm{rpm}$; dosage: $0.5 \mathrm{~g} / 100 \mathrm{~mL}$, Conc. MG equal Conc. MB: $100 \mathrm{mg} / \mathrm{L}$ ).

\subsection{Adsorption Isotherms for Single and Binary Systems}

Adsorption isotherm is fundamental to the design of adsorption systems; it demonstrates the relationship between a specific adsorbate and an adsorbent. The Langmuir and Freundlich isotherms parameters were calculated for a single adsorption system and presented in Table 2. Equilibrium data for a single adsorption study was well described by the Freundlich model.

Table 2. Adsorption isotherms constants for adsorption of MG and MB dye in single system.

\begin{tabular}{ccccc}
\hline Dye & \multicolumn{2}{c}{ Langmuir } & \multicolumn{2}{c}{ Freundlich } \\
\hline \multirow{3}{*}{$\mathrm{MG}$} & $q_{\max }(\mathrm{mg} / \mathrm{g})$ & 429.18 & $K_{F}(\mathrm{~L} / \mathrm{mg})$ & 9.341 \\
& $K_{L}(\mathrm{mg} / \mathrm{g})$ & 0.0188 & $n$ & 1.179 \\
$R^{2}$ & 0.8137 & $R^{2}$ & 0.9990 \\
\hline \multirow{2}{*}{$\mathrm{MB}$} & $q_{\max }(\mathrm{mg} / \mathrm{g})$ & 308.64 & $K_{F}(\mathrm{~L} / \mathrm{mg})$ & 0.028 \\
& $K_{L}(\mathrm{mg} / \mathrm{g})$ & 0.0476 & $n$ & 1.283 \\
& $R^{2}$ & 0.8927 & $R^{2}$ & 0.9994 \\
\hline
\end{tabular}

Table 3 presents the equilibrium adsorption Langmuir model parameters for MG and MB dyes uptake by TMPAA in binary adsorption scheme. As expected, the maximum adsorption capacities, $q_{\max }$ of TMPAA for MG and MB dyes entrapment in binary solutions, were respectively found to be $150.97 \mathrm{mg} / \mathrm{g}$ and $124.61 \mathrm{mg} / \mathrm{g}$. While $429.18 \mathrm{mg} / \mathrm{g}$ and $308.64 \mathrm{mg} / \mathrm{g}$ were the maximum adsorption capacities of TMPAA for MG and MB dyes, respectively in a single solution (Table 2). The results exhibit that the adsorption capacity of the modified polymer for cationic dyes declined in the binary system related to a single solution. This is attributed to the fact that in the binary system, partial or total competitions between adsorbate ions for the binding sites on TMPAA surface occur and act as the entrapment-governing aspect. Besides, adsorption affinity of the modified polymer surface is mutually hindered by lateral interaction and rivalry between MG/MB components for the occupancy of sorption site [31,52]. A similar observation was reported Kurniawan et al. (2012) for the uptake of basic dyes in a binary system by rarasaponin-bentonite [53]. Ziane and coworkers (2018) report reduction in adsorption capacities of modified dolomite (D900), for the removal of Reactive Black 5 (RB5) and Congo 
Red (CR) from wastewater containing a mixture of two dyes. According to their report, the single and binary maximum sorption capacities were $51.81 \mathrm{mg} / \mathrm{g}$ and $44.57 \mathrm{mg} / \mathrm{g}$ (RB5), and $261.36 \mathrm{mg} / \mathrm{g}$ and $153.04 \mathrm{mg} / \mathrm{g}(\mathrm{CR})$, respectively [54]. Also, the batch adsorption experiment performed by Maleki and team showed that the maximum adsorption capacity of amine-functionalized multi-walled carbon nanotubes for the uptake of Acid Blue 45 (AB45) and Acid Black 1 (AB1) dyes in binary system were $625 \mathrm{mg} / \mathrm{g}$ and $666 \mathrm{mg} / \mathrm{g}$ respectively, while the maximum adsorption capacity in single solution was $666 \mathrm{mg} / \mathrm{g}$ and $714 \mathrm{mg} / \mathrm{g}$ [15].

Table 3. Langmuir isotherm constants at $25^{\circ} \mathrm{C}$ for the adsorption of MG and MB dyes on TMPAA in the binary system.

\begin{tabular}{cccc}
\hline \multirow{2}{*}{ Dye in a Binary System } & \multicolumn{3}{c}{ Langmuir Constants } \\
\cline { 2 - 4 } & $\boldsymbol{q}_{\max }(\mathbf{m g} / \mathbf{g})$ & $\boldsymbol{K}_{\mathbf{L}}(\mathrm{L} / \mathbf{m g})$ & $\boldsymbol{R}^{2}$ \\
\hline $\mathrm{MG}$ & 150.97 & 0.0021 & 0.8357 \\
$\mathrm{MB}$ & 124.61 & 0.0017 & 0.9309 \\
\hline
\end{tabular}

Isotherm studies of binary cationic MG and MB dyes adsorption were further analyzed using extended Langmuir equation (ELE) and extended Freundlich equation (EFE), respectively.

\subsubsection{Extended Freundlich Equation (EFE) for Binary Cationic Dye System}

Figures 9 and 10 illustrated the assessment of experimental adsorption data with theoretical values generated from the extended Langmuir equations for binary cationic dye solution. The sum of squares error, SSE, estimated between the experimental adsorption capacity and extended Langmuir isotherm prediction for MG and MB in binary solution are 618 and 736, respectively (Table 4). The application of the extended Langmuir equations in the extrapolation of adsorption capacity of TMPAA for MG and MB dyes results in good agreement with the experimental adsorbent capacity especially at higher initial dye concentrations. However, the fundamental assumptions upon which the Langmuir model is based gave no lateral interaction between adsorbed moieties and equal independent rivalry between adsorbate components. This outcome is supported by the research findings of Yang and team (2016) for competitive adsorption of heavy metal ions using modified green tea waste [55].

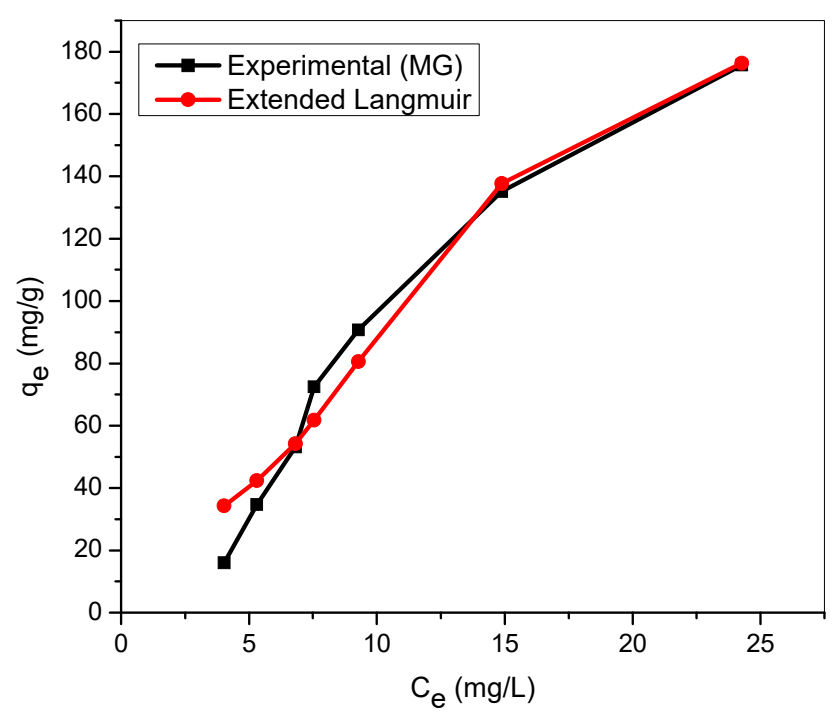

Figure 9. Extended Langmuir model for MG in binary system with $\mathrm{MB}$ (temperature: $25^{\circ} \mathrm{C}$; agitation speed: $100 \mathrm{rpm}$; dosage: $0.5 \mathrm{~g} / 100 \mathrm{~mL}$, Conc. MG = Conc. MB: (20-200 mg/L)). 


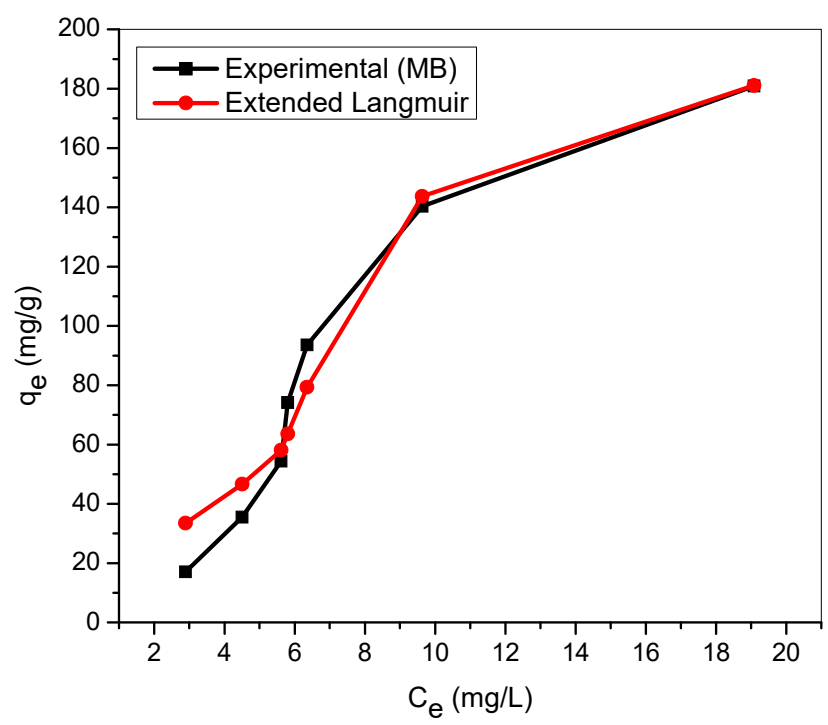

Figure 10. Extended Langmuir model for $\mathrm{MB}$ in binary system with $\mathrm{MG}$ (temperature: $25^{\circ} \mathrm{C}$; agitation speed: $100 \mathrm{rpm}$; dosage: $0.5 \mathrm{~g} / 100 \mathrm{~mL}$, Conc. MG = Conc. MB: (20-200 mg/L)).

Table 4. Parameters of the extended Langmuir model for the binary adsorption of MG and MB by the TMPAA.

\begin{tabular}{cccc}
\hline \multirow{2}{*}{ Dye in a Binary System } & \multicolumn{3}{c}{ Model Constants } \\
\cline { 2 - 4 } & $\boldsymbol{K}_{1}$ & $\boldsymbol{K}_{2}$ & $\boldsymbol{S S E}$ \\
\hline MG & -0.0629 & 0.0891 & 618.12 \\
MB & -0.1281 & 0.1734 & 735.52 \\
\hline
\end{tabular}

\subsubsection{Extended Freundlich Equation (EFE) for Binary Cationic Dye System}

In a binary cationic dye (MG and $\mathrm{MB})$ mixture, the individual adsorption capacity $\left(q_{e, M G}, q_{e, M B}\right)$ is estimated according to the following extended Freundlich models (derived from Equations (11) and (12)):

$$
\begin{aligned}
q_{e, M G} & =\frac{9.341\left(C_{e, M G}\right)\left(\frac{1}{1.179}\right)+x_{1}}{C_{e, M G}^{x_{1}}+y_{1} C_{e, M B}^{z_{1}}} \\
q_{e, M B} & =\frac{0.028\left(C_{e, M B}\right)\left(\frac{1}{1.283}\right)+x_{2}}{C_{e, M B}^{x_{2}}+y_{2} C_{e, M G}^{z_{2}}}
\end{aligned}
$$

Figures 11 and 12 show the comparison of the experimental sorption capacity with the predicted values by extended Freundlich model for binary dye system. The isotherm was found suitable for the description of MG and MB adsorption, simultaneously. This phenomenon agreed with the findings of Remenarova et al. (2009) for the binary biosorption of malachite green (MG), auramine O (BY2), and thioflavine T (BY1) by moss rhytidiadelphus squarrosus [56]. The model parameters obtained and the sum of squares errors are tabulated in Table 5. The SSE values, 696 (MG), 681 (MB) are found comparable relatively to the one presented in the extended Langmuir isotherm (618 for MG; 735 for MB). However, both extended Langmuir and extended Freundlich failed to account for the type of interactions that existed between the cationic MG and MB molecules. 


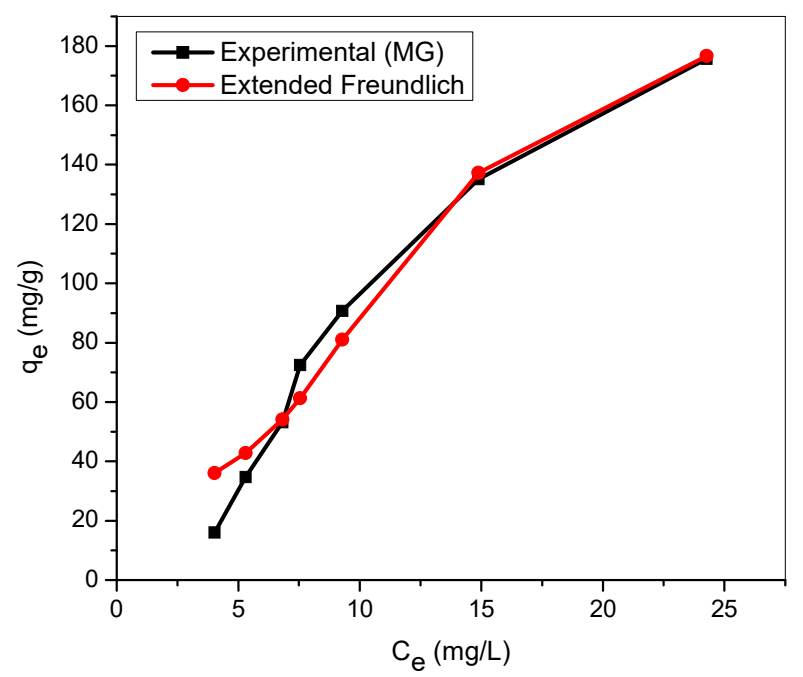

Figure 11. Extended Freundlich model for MG in binary system with $\mathrm{MB}$ (temperature: $25^{\circ} \mathrm{C}$; agitation speed: $100 \mathrm{rpm}$; dosage: $0.5 \mathrm{~g} / 100 \mathrm{~mL}$, Conc. MG = Conc. MB: (20-200 mg/L)).

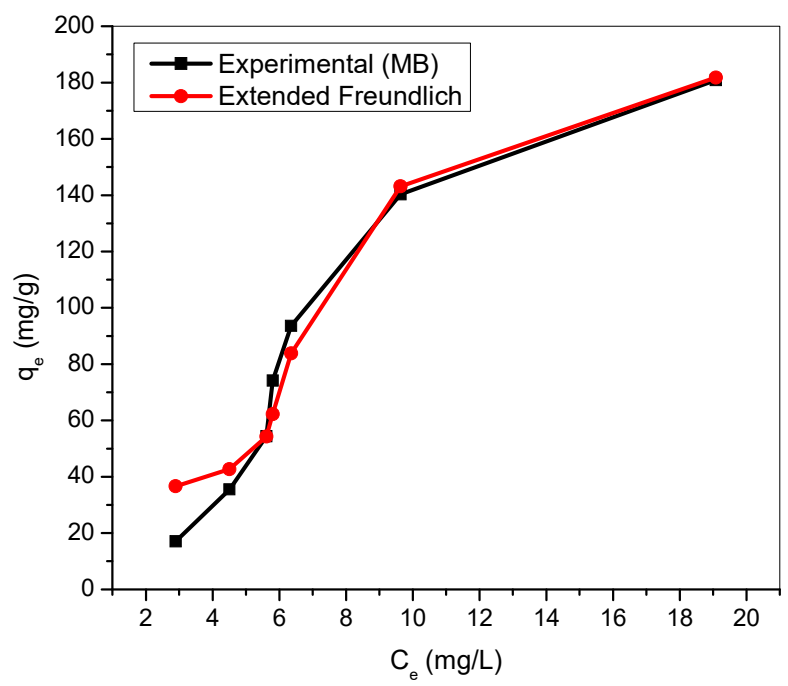

Figure 12. Extended Freundlich model for MB in binary system with MG (temperature: $25^{\circ} \mathrm{C}$; agitation speed: $100 \mathrm{rpm}$; dosage: $0.5 \mathrm{~g} / 100 \mathrm{~mL}$, Conc. MG = Conc. MB: (20-200 mg/L)).

Table 5. Parameters of the extended Freundlich model for the binary adsorption of MG and MB by the TMPAA.

\begin{tabular}{ccccc}
\hline \multirow{2}{*}{ The Dye in the Binary System } & \multicolumn{4}{c}{ Model Constants } \\
\cline { 2 - 5 } & $x_{\boldsymbol{i}}$ & $y_{\boldsymbol{i}}$ & $z_{\boldsymbol{i}}$ & \multicolumn{5}{c}{ SSE } \\
\hline MG & -3.412 & -0.095 & -3.095 & 695.90 \\
MB & -0.1281 & 0.1734 & 735.52 & 680.66 \\
\hline
\end{tabular}

Table 6 displays the competition constants and the interactive effects of MG and MB in the binary system. The calculated $\mathrm{P}$ factor $\left(P_{f i}\right)$ for both cationic dyes was greater than one, indicating that the adsorption of component $i(\mathrm{MG} / \mathrm{MB})$ is inhibited by the presence of another component (MB/MG) [37]. Besides, the higher value of the inhibitory effect $(\Delta I E)$ demonstrates that the entrapment of MG is suppressed in the presence of MB dye. This is corroborated by the estimated selectivity ratio, $S_{(M G / M B)}$ value that is greater than unity. The results confirmed that the TMPAA polymeric adsorbent has more affinity towards MG than MB [57]. Similar antagonistic analogous trends could be noticed also in the binary dyes solution of remazol brilliant blue (RBB) and disperse orange (DO) [58], methylene blue (MB) and methyl orange (MO) [59], and methyl orange (MO) and phenol [41]. 
Table 6. Competition constants and interaction effects of MG and MB by the TMPAA in a binary solution.

\begin{tabular}{ccccc}
\hline The Dye in a & \multicolumn{4}{c}{ Competition Constants } \\
\cline { 2 - 5 } Binary System & $\boldsymbol{P}_{\boldsymbol{f} i}$ & $\Delta \boldsymbol{I E}$ & $\boldsymbol{S}_{(i / j)}$ & Interactive Effect \\
\hline MG & 2.843 & 0.648 & 1.2115 & Antagonistic \\
MB & 2.477 & 0.596 & 0.8254 & Antagonistic \\
\hline
\end{tabular}

\subsection{Adsorption Kinetics}

In order to determine the order and kinetics of the binary adsorption process, pseudo-first order (PFO) and pseudo-second-order (PSO) models were tested. The kinetic data were fitted into the PFO (Figure 13) and PSO (Figure 14) for the adsorption of MG and MB dye by TMPAA in a binary system. The kinetic factors and correlation coefficient gotten are presented in Table 7.
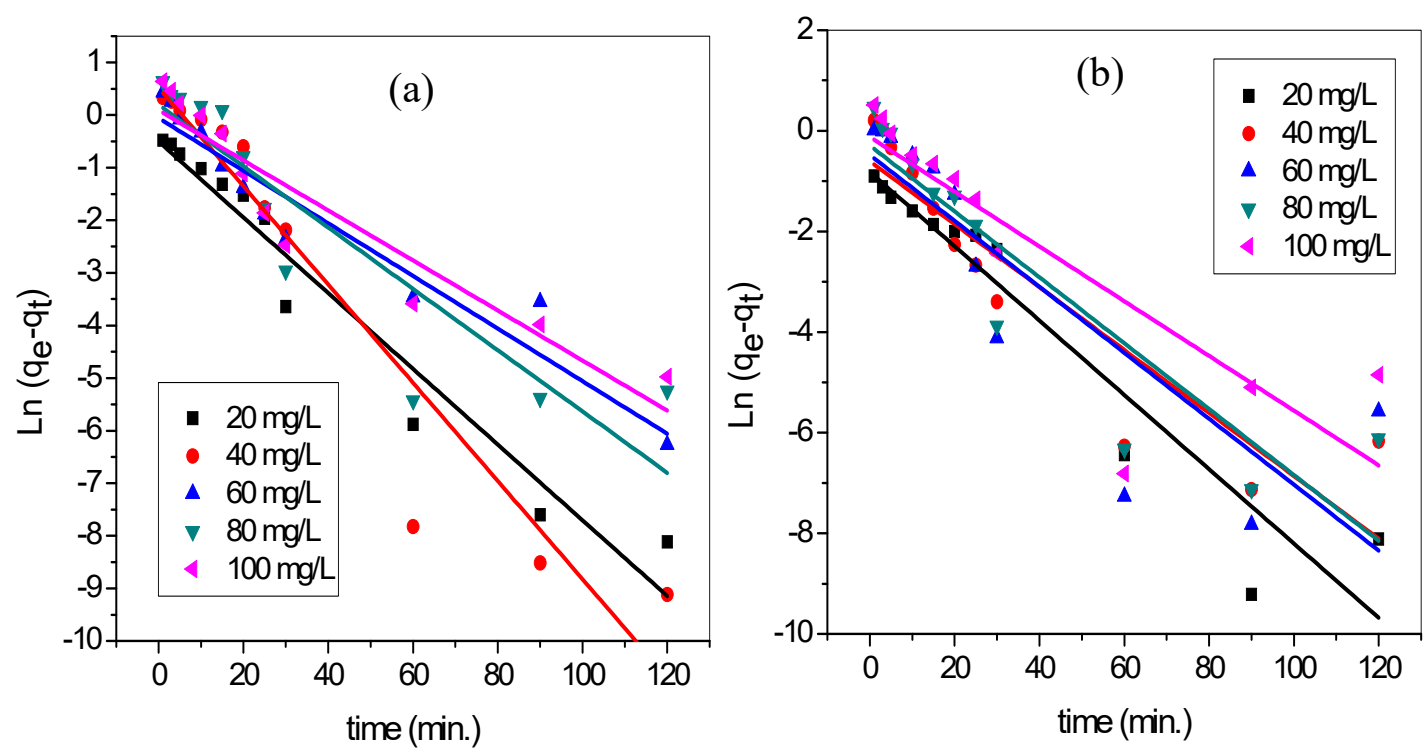

Figure 13. PFO model for (a) MG and (b) MB adsorption in binary system with MB (temperature: $25^{\circ} \mathrm{C}$; speed: $100 \mathrm{rpm}$; dose: $0.5 \mathrm{~g} / 100 \mathrm{~mL}$; Conc. $\mathrm{MG}=$ Conc. $\left.\mathrm{MB}\right)$.
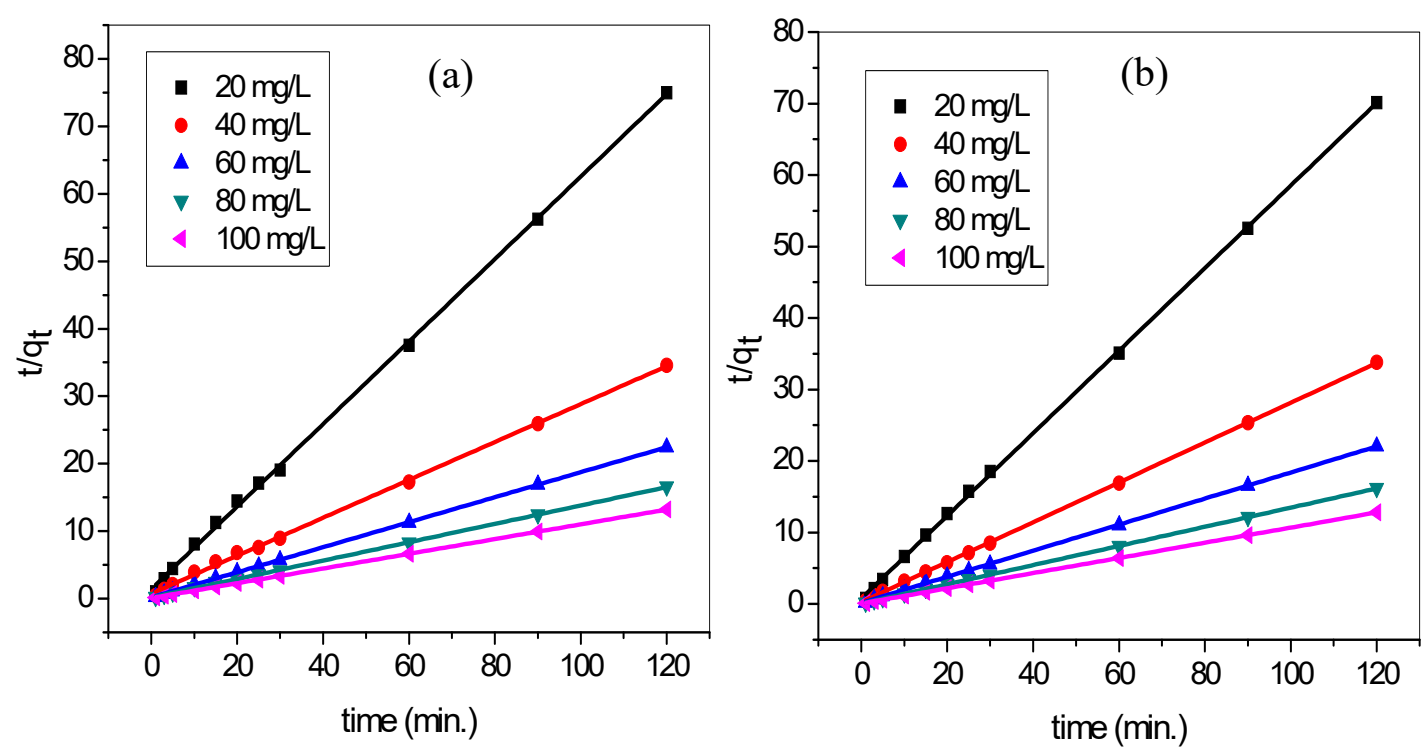

Figure 14. PSO model for (a) MG and (b) MB adsorption in binary system with MB (temperature: $25^{\circ} \mathrm{C}$; speed: $100 \mathrm{rpm}$; dose: $0.5 \mathrm{~g} / 100 \mathrm{~mL}$; Conc. $\mathrm{MG}=$ Conc. $\mathrm{MB}$ ). 
The PFO equation did not rank as favorable based on the correlation coefficient $R^{2}$ values (0.7035-0.9471). The MG and MB dye equilibrium concentration on the TMPAA, $q_{e(\text { cal })}$ did not correlate to the experimental values $q_{e(\exp )}$, this further discrediting its suitability. Conversely, the PSO kinetic model adjudged well fitted the adsorption data with higher $R^{2}$ values (0.999-1). In addition, the calculated values of $q_{e(c a l)}$ showed good agreement with the corresponding experimental values $q_{e(\exp )}$ for the range of initial concentrations investigated. This confirmed the suitability of the PSO model for the description of the adsorption process. Thus, the sorption process involves transferring and or sharing of electron between anionic TMPAA adsorbent and cationic dyes. Therefore, chemisorption was found to be the rate-limiting step, controlling the adsorption of MG and MB molecules onto TMPAA.

Table 7. Kinetic parameters and correlation coefficient for PFO and PSO kinetic models for adsorption MG and MB by TMPAA in the binary system.

\begin{tabular}{|c|c|c|c|c|c|c|c|c|}
\hline \multirow{2}{*}{$\begin{array}{c}\text { The Dye in } \\
\text { a Binary } \\
\text { System }\end{array}$} & \multirow{2}{*}{$\begin{array}{c}\text { Initial Dye } \\
\text { Concentration } \\
C_{o}(\mathrm{mg} / \mathrm{L})\end{array}$} & \multirow{2}{*}{$\begin{array}{l}q_{e(\exp )} \\
(\mathrm{mg} / \mathrm{g})\end{array}$} & \multicolumn{3}{|c|}{$\begin{array}{c}\text { PFO } \\
\text { Kinetic Model }\end{array}$} & \multicolumn{3}{|c|}{$\begin{array}{c}\text { PSO } \\
\text { Kinetic Model }\end{array}$} \\
\hline & & & $\begin{array}{c}q_{e(c a l)} \\
(\mathrm{mg} / \mathrm{g})\end{array}$ & $\begin{array}{c}k_{1} \\
\left(\min ^{-1}\right)\end{array}$ & $R^{2}$ & $\begin{array}{c}q_{e(c a l)} \\
(\mathrm{mg} / \mathrm{g})\end{array}$ & $\begin{array}{c}k_{2} \\
(\mathrm{~g} / \mathrm{mg} \cdot \mathrm{min})\end{array}$ & $R^{2}$ \\
\hline \multirow{5}{*}{ MG } & 20 & 1.60 & 0.60 & 0.072 & 0.9471 & 1.63 & 0.268 & 0.9993 \\
\hline & 40 & 3.47 & 1.67 & 0.093 & 0.9128 & 3.56 & 0.108 & 0.9989 \\
\hline & 60 & 5.35 & 0.95 & 0.050 & 0.9209 & 5.39 & 0.181 & 0.9993 \\
\hline & 80 & 7.25 & 1.21 & 0.058 & 0.8092 & 7.34 & 0.107 & 0.9996 \\
\hline & 100 & 9.10 & 1.10 & 0.048 & 0.8843 & 9.16 & 0.139 & 0.9999 \\
\hline \multirow{5}{*}{$\mathrm{MB}$} & 20 & 1.71 & 0.44 & 0.074 & 0.9048 & 1.73 & 0.433 & 0.9997 \\
\hline & 40 & 3.55 & 0.55 & 0.063 & 0.8221 & 3.58 & 0.285 & 0.9999 \\
\hline & 60 & 5.44 & 0.62 & 0.066 & 0.7082 & 5.48 & 0.214 & 0.9999 \\
\hline & 80 & 7.42 & 0.75 & 0.065 & 0.8101 & 7.46 & 0.225 & 1 \\
\hline & 100 & 9.37 & 0.88 & 0.054 & 0.7035 & 9.42 & 0.169 & 1 \\
\hline
\end{tabular}

\subsection{FTIR and SEM Analyses}

Fourier transform infrared (FTIR) spectroscopy and scanning electron microscopy (SEM) are potent tools for delineating adsorption mechanism. FTIR spectra were recorded for the TMPAA adsorbent before and after dye uptake in the $4000-500 \mathrm{~cm}^{-1}$ (Figure 15). Some absorption peaks of the polymeric adsorbent are found slightly shifted in the spectrum of the MG and MB dye loaded adsorbent. The peak at $3345 \mathrm{~cm}^{-1}\left(-\mathrm{NH}_{2} /-\mathrm{OH}\right), 1728 \mathrm{~cm}^{-1}(-\mathrm{C}=\mathrm{O})$, and $729 \mathrm{~cm}^{-1}(-\mathrm{C}=\mathrm{S})$ in unloaded adsorbent are shifted to $3319 \mathrm{~cm}^{-1}, 1736 \mathrm{~cm}^{-1}$, and $733 \mathrm{~cm}^{-1}$ on the TMPAA after coadsorption of MG and MB cationic dyes. These characteristic surface-functional groups are essential to the sorption capacity of the adsorbent. Thus, strong interactions exist between adsorbate and adsorbent [54,60], probably consisting of inner-sphere surface complexation. This is due to electrostatic attraction between TMPAA-MG/MB. A similar phenomenon was reported by [61] on the adsorption of chromotrope dye onto activated carbon and [62] for the uptake of emerging pharmaceutical contaminants.

Insightful information concerning the morphological features of the TMPAA is provided by SEM analysis. SEM image of the unloaded adsorbent (Figure 16a) shows the rough and non-uniform surface of the TMPAA. Post cationic dyes adsorption, a significant change is seen in the structure of the adsorbent (Figure 16b). Its voids appear to be occupied and covered with shinning and bulky molecules of the MG and MB dye. Lata et al. (2008), Hameed et al. (2017) and Sekulic group (2019) reported similar findings [61-63]. 


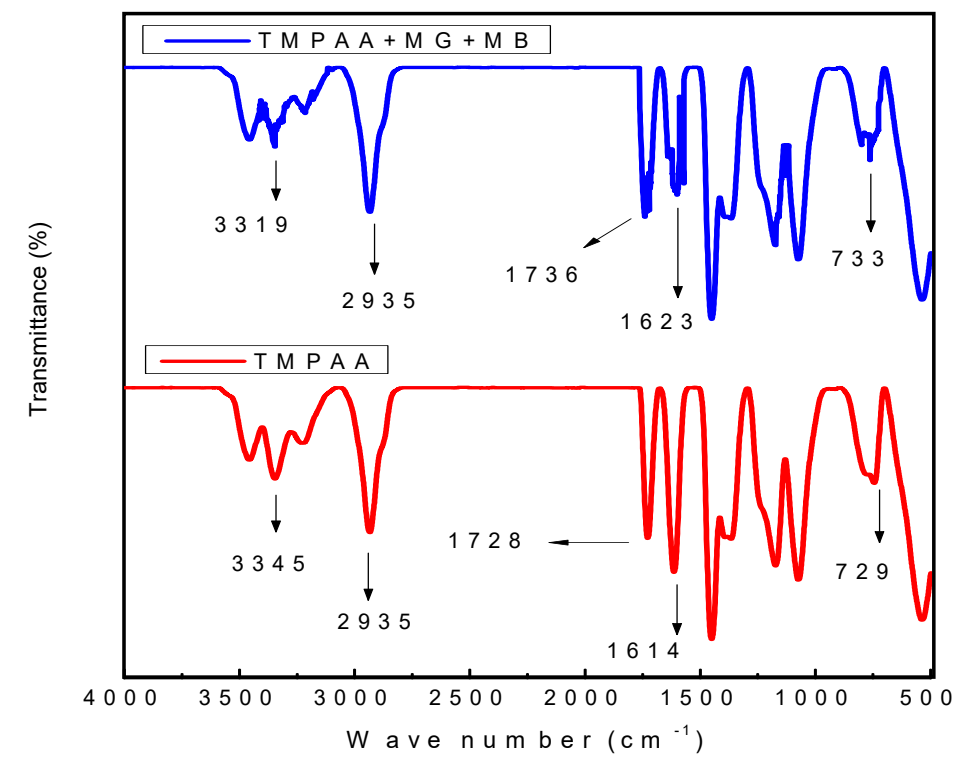

Figure 15. FTIR spectra of synthesized TMPAA (red) and TMPAA loaded with MG and MB dyes (blue).
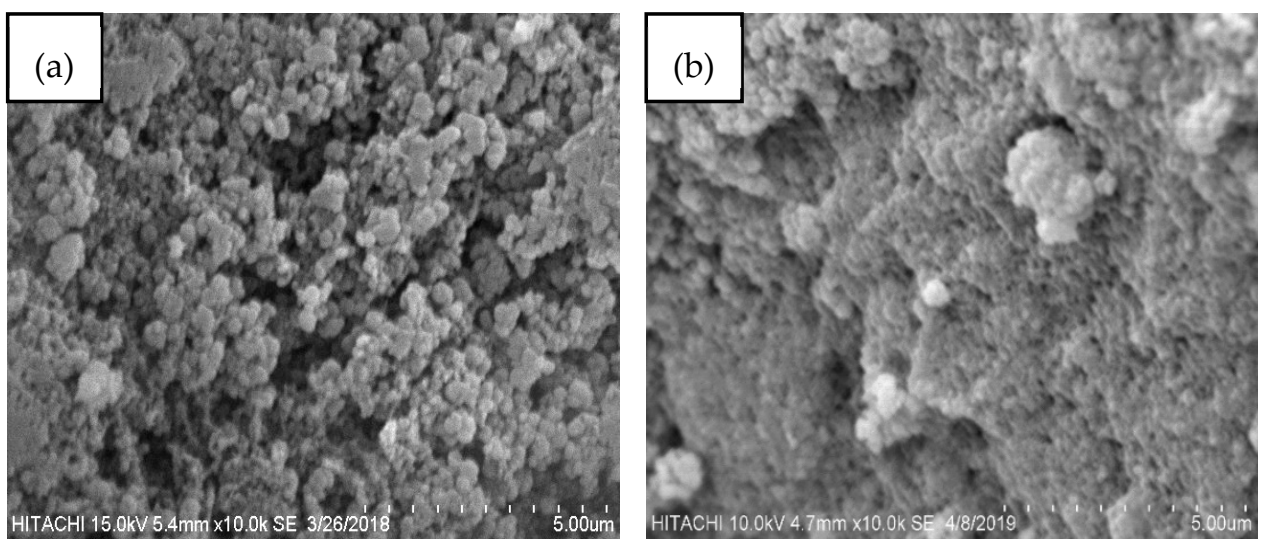

Figure 16. SEM micrographs of (a) TMPAA and (b) TMPAA loaded with MG and MB dyes.

\section{Conclusions}

The competitive adsorption of cationic MG and MB dye under equimolar conditions on TMPAA adsorbent was investigated. The comparison delineates an antagonistic interaction between the MG and MB molecules, which mutually hindered the adsorption of both dyes on the TMPAA. The polymeric adsorbent shows higher affinity towards MG entrapment than MB in the binary system, viz. $150 \mathrm{mg} / \mathrm{g}$ against $124 \mathrm{mg} / \mathrm{g}$ at equilibrium. Extended Langmuir and extended Freundlich equations give a good estimation of the binary equilibrium data. Pseudo-second-order model fits suitably the coadsorption kinetics, which indicates chemisorption between the dye ions and TMPAA sorbent. According to this study, TMPAA could prove to be an attractive functional adsorbent when discrimination in the separation of cationic dyes from liquid phase is essential. This work could also offer theoretical guidance for the treatment of multicomponent industrial wastewater.

Author Contributions: Conceptualization, S.N.A.M.J. and L.C.A.; Methodology, S.N.A.M.J., T.S.Y.C. and A.A.A.; Resources, S.N.A.M.J. and L.C.A.; Supervision, T.S.Y.C. and L.C.A.; Investigation, A.A.A., K.L.L. and M.A.; Writing-Original Draft Preparation, A.A.A., K.L.L. and M.A.; Review and Editing, S.N.A.M.J, and A.A.A.

Funding: The work was financially supported by the Geran IPB Universiti Putra Malaysia (UPM) Malaysia, with project code; GP-IPB/2017/9542400. 
Acknowledgments: The authors acknowledge the Department of Chemical and Environmental Engineering, Faculty of Engineering, and Chemistry Department, Faculty of Science, Universiti Putra Malaysia (UPM) for the research facilities.

Conflicts of Interest: The authors hereby declare no conflict of interests regarding the publication of this article.

\section{References}

1. Chaúque, E.F.C.; Dlamini, L.N.; Adelodun, A.A.; Greyling, C.J.; Ngila, J.C. Electrospun polyacrylonitrile nanofibers functionalized with EDTA for adsorption of ionic dyes. Phys. Chem. Earth 2017, 100, $201-211$. [CrossRef]

2. Hokkanen, S.; Bhatnagar, A.; Sillanpää, M. A review on modification methods to cellulose-based adsorbents to improve adsorption capacity. Water Res. 2016, 91, 156-173. [CrossRef] [PubMed]

3. Abhishek, L.; Abishek, R.; Deepak, K.K.; Sivakumar, G. Advanced Water Treatment Using Nano- Materials. Int. J. Innov. Res. Sci. Eng. Technol. 2014, 3, 17130-17138.

4. Hai, F.I.; Yamamoto, K.; Nakajima, F.; Fukushi, K. Bioaugmented membrane bioreactor (MBR) with GAC-packed zone for high rate textile wastewater treatment. Water Res. 2011, 45, 2199-2206. [CrossRef] [PubMed]

5. Chen, D.; Wang, L.; Ma, Y.; Yang, W. Super-adsorbent material based on functional polymer particles with a multilevel porous structure. NPG Asia Mater. 2016, 1-9. [CrossRef]

6. Tan, K.B.; Vakili, M.; Horri, B.A.; Poh, P.E.; Abdullah, A.Z.; Salamatinia, B. Adsorption of dyes by nanomaterials: Recent developments and adsorption mechanisms. Sep. Purif. Technol. 2015, 150, $229-242$. [CrossRef]

7. Zhang, G.; Yi, L.; Deng, H.; Sun, P. Dyes adsorption using a synthetic carboxymethyl cellulose-acrylic acid adsorbent. J. Environ. Sci. 2014, 26, 1203-1211. [CrossRef]

8. Zhang, Y.Z.; Li, J.; Zhao, J.; Bian, W.; Li, Y.; Wang, X.J. Adsorption behavior of modified Iron stick yam skin with Polyethyleneimine as a potential biosorbent for the removal of anionic dyes in single and ternary systems at low temperature. Bioresour. Technol. 2016, 222, 285-293. [CrossRef]

9. Yemendzhiev, H.; Alexieva, Z.; Krastanov, A. Decolorization of synthetic dye reactive blue 4 by mycelial culture of white-rot fungi trametes versicolor 1. Biotechnol. Biotechnol. Equip. 2009, 23, 230-232. [CrossRef]

10. Sengupta, R.; Chakraborty, S.; Bandyopadhyay, S.; Dasgupta, S.; Mukhopadhyay, R.; Auddy, K.; Deuri, A.S. A Short Review on Rubber/Clay Nanocomposites With Emphasis on Mechanical Properties. Engineering 2007, 47, 21-25. [CrossRef]

11. García-Mateos, F.J.; Ruiz-Rosas, R.; Marqués, M.D.; Cotoruelo, L.M.; Rodríguez-Mirasol, J.; Cordero, T. Removal of paracetamol on biomass-derived activated carbon: Modeling the fixed bed breakthrough curves using batch adsorption experiments. Chem. Eng. J. 2015, 279, 18-30. [CrossRef]

12. Wang, L.; Xing, R.; Liu, S.; Yu, H.; Qin, Y.; Li, K.; Feng, J.; Li, R.; Li, P. Recovery of silver (I) using a thiourea-modified chitosan resin. J. Hazard. Mater. 2010, 180, 577-582. [CrossRef] [PubMed]

13. Zhu, Y.; Bai, Z.S.; Wang, H.L. Microfluidic synthesis of thiourea modified chitosan microsphere of high specific surface area for heavy metal wastewater treatment. Chin. Chem. Lett. 2017, 28, 633-641. [CrossRef]

14. Varaprasad, K.; Jayaramudu, T.; Sadiku, E.R. Removal of dye by carboxymethyl cellulose, acrylamide and graphene oxide via a free radical polymerization process. Carbohydr. Polym. 2017, 164, 186-194. [CrossRef] [PubMed]

15. Maleki, A.; Hamesadeghi, U.; Daraei, H.; Hayati, B.; Najafi, F.; McKay, G.; Rezaee, R. Amine functionalized multi-walled carbon nanotubes: Single and binary systems for high capacity dye removal. Chem. Eng. J. 2017, 313, 826-835. [CrossRef]

16. Wang, L.; Xing, R.; Liu, S.; Qin, Y.; Li, K.; Yu, H.; Li, R.; Li, P. Studies on adsorption behavior of Pb(II) onto a thiourea-modified chitosan resin with $\mathrm{Pb}$ (II) as template. Carbohydr. Polym. 2010, 81, 305-310. [CrossRef]

17. Qin, Y.; Wang, L.; Zhao, C.; Chen, D.; Ma, Y.; Yang, W. Ammonium-Functionalized Hollow Polymer Particles As a pH-Responsive Adsorbent for Selective Removal of Acid Dye. ACS Appl. Mater. Interfaces 2016, 8, 16690-16698. [CrossRef] [PubMed]

18. Zahri, N.A.M.; Jamil, S.N.A.M.; Abdullah, L.C.; Yaw, T.C.S.; Mobarekeh, M.N.; Huey, S.J.; Rapeia, N.S.M. Improved method for preparation of amidoxime modified poly(acrylonitrile-co-acrylic acid): Characterizations and adsorption case study. Polymers (Basel) 2015, 7, 1205-1220. [CrossRef] 
19. El-korashy, S.A.; Elwakeel, K.Z.; El-hafeiz, A.A. Fabrication of bentonite/thiourea-formaldehyde composite material for $\mathrm{Pb}$ (II), Mn (VII) and $\mathrm{Cr}$ (VI) sorption: A combined basic study and industrial application. J. Clean. Prod. 2016, 137, 40-50. [CrossRef]

20. Adeyi, A.A.; Jamil, S.N.A.M.; Abdullah, L.C.; Choong, T.S.Y. Adsorption of Malachite Green Dye from Liquid Phase Using Hydrophilic Thiourea-Modified Poly (acrylonitrile-co-acrylic acid): Kinetic and Isotherm Studies. J. Chem. 2019, 2019, 1-14. [CrossRef]

21. Adeyi, A.A.; Jamil, S.N.A.M.; Abdullah, L.C.; Choong, T.S.Y. Hydrophilic thiourea-modified poly(acrylonitrile-co-acrylic acid) adsorbent: Preparation, characterization, and dye removal performance. Iran. Polym. J. 2019, 28, 483-491. [CrossRef]

22. Adeyi, A.A.; Jamil, S.N.A.M.; Abdullal, L.C.; Choong, T.S.Y.; Lau, K.L.; Abdullah, M. Adsorptive Removal of Methylene Blue from Aquatic environment using thiourea modified poly(acrylonitrile-co-acrylic acid). Materials 2019, 12, 1-17. [CrossRef] [PubMed]

23. Meevasana, K.; Pavasant, P. Quantitative measurement techniques for binary dye mixtures: A case study in an adsorption system. Sci. Asia 2008, 34, 390-394. [CrossRef]

24. Zou, W.; Liu, L.; Li, H.; Han, X. Investigation of synergistic adsorption between methyl orange and Cd(II) from binary mixtures on magnesium hydroxide modified clinoptilolite. Korean J. Chem. Eng. 2016, 33, 2073-2083. [CrossRef]

25. Atar, N.; Olgun, A.; Wang, S.; Liu, S. Adsorption of Anionic Dyes on Boron Industry Waste in Single and Binary Solutions Using Batch and Fixed-Bed Systems. J. Chem. Eng. Data 2011, 56, 508-516. [CrossRef]

26. Janaki, V.; Vijayaraghavan, K.; Ramasamy, A.K.; Lee, K.; Oh, B.; Kamala-kannan, S. Competitive adsorption of Reactive Orange 16 and Reactive Brilliant Blue R on polyaniline/bacterial extracellular polysaccharides composite-A novel eco-friendly polymer. J. Hazard. Mater. 2012, 242, 110-117. [CrossRef] [PubMed]

27. Ayawei, N.; Ebelegi, A.N.; Wankasi, D. Modelling and Interpretation of Adsorption Isotherms. J. Chem. 2017, 2017, 1-11. [CrossRef]

28. Foo, K.Y.; Hameed, B.H. Preparation, characterization and evaluation of adsorptive properties of orange peel based activated carbon via microwave induced K2CO3activation. Bioresour. Technol. 2012, 104, 679-686. [CrossRef]

29. Shahbeig, H.; Bagheri, N.; Ghorbanian, S.A.; Ahmad, H.; Poorkarimi, S. A new adsortption isotherm model of aqueous solutions on granular activited carbon.pdf. World J. Model. Simul. 2013, 9, 243-254.

30. Girish, C.R. Various Isotherm Models for Multicomponent Adsorption: A Review. Int. J. Civ. Eng. Technol. 2017, 8, 80-86.

31. Sharma, K.; Vyas, R.K.; Singh, K.; Dalai, A.K. Degradation of a synthetic binary dye mixture using reactive adsorption: Experimental and modeling studies. J. Environ. Chem. Eng. 2018, 6, 5732-5743. [CrossRef]

32. Ma, G.; Liu, Y.; Lei, Z.; Zhou, P.; Luo, X.; Zhang, Z. Synergic adsorption of acid blue 80 and heavy metal ions (Cu2+/Ni2+) onto activated carbon and its mechanisms. J. Ind. Eng. Chem. 2015, 27, 164-174.

33. Leodopoulos, C.; Doulia, D.; Gimouhopoulos, K.; Triantis, T.M. Single and simultaneous adsorption of methyl orange and humic acid onto bentonite. Appl. Clay Sci. 2012, 70, 84-90. [CrossRef]

34. Laabd, M.; Chafai, H.; Essekri, A.; Elamine, M.; Al-muhtaseb, S.A.; Lakhmiri, R.; Albourine, A. Single and multi-component adsorption of aromatic acids using an eco- friendly polyaniline-based biocomposite. Sustain. Mater. Technol. 2017, 12, 35-43. [CrossRef]

35. Wang, F.; Pan, Y.; Cai, P.; Guo, T.; Xiao, H. Single and binary adsorption of heavy metal ions from aqueous solutions using sugarcane cellulose-based adsorbent. Bioresour. Technol. 2017, 241, 482-490. [CrossRef] [PubMed]

36. Choy, K.K.H.; Porter, J.F.; Mckay, G. Langmuir Isotherm Models Applied to the Multicomponent Sorption of Acid Dyes from Effluent onto Activated Carbon. J. Chem. Eng. Data 2000, 45, 575-584. [CrossRef]

37. Girish, C.R. Simultaneous adsorption of pollutants onto the adsorbent review of interaction mechanism between the pollutants and the adsorbent. Int. J. Eng. Technol. 2018, 7, 3613-3622.

38. Wu, Y.; Jiang, L.; Wen, Y.; Zhou, J. Biosorption of Basic Violet 5BN and Basic Green by waste brewery 's yeast from single and multicomponent systems. Environ. Sci. Pollut. Res. 2012, 19, 510-521. [CrossRef]

39. Anna, B.; Kleopas, M. Adsorption of Cd (II), Cu (II), Ni (II) and Pb (II) onto natural bentonite: Study in monoand multi-metal systems. Environ. Earth Sci. 2015, 73, 5435-5444. [CrossRef]

40. Sdiri, A.T.; Higashi, T.; Jamoussi, F. Adsorption of copper and zinc onto natural clay in single and binary systems. Int. J. Environ. Sci. Technol. 2014, 11, 1081-1092. [CrossRef] 
41. Istratie, R.; Stoia, M.; Pa, C. Single and simultaneous adsorption of methyl orange and phenol onto magnetic iron oxide/carbon nanocomposites. Arab. J. Chem. 2016. [CrossRef]

42. Zhang, L.; Wei, J.; Zhao, X.; Li, F.; Jiang, F.; Zhang, M.; Cheng, X. Competitive adsorption of strontium and cobalt onto tin antimonate. Chem. Eng. J. 2016, 285, 679-689. [CrossRef]

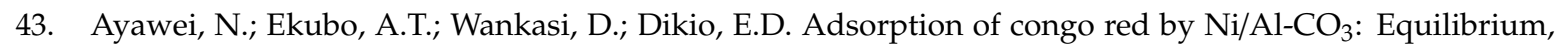
thermodynamic and kinetic studies. Orient. J. Chem. 2015, 31, 1307-1318. [CrossRef]

44. Ho, Y.S. Second-order kinetic model for the sorption of cadmium onto tree fern: A comparison of linear and non-linear methods. Water Res. 2006, 40, 119-125. [CrossRef] [PubMed]

45. Zhou, X.; Zheng, P.; Wang, L.; Liu, X. Preparation of Sulfonated Poly (arylene ether nitrile) -Based Adsorbent as a Highly Selective and efficient adsorbent for cationic dyes. Polymers 2019, 11, 1-17. [CrossRef] [PubMed]

46. Charumathi, D.; Das, N. Packed bed column studies for the removal of synthetic dyes from textile wastewater using immobilised dead C. tropicalis. Desal. 2012, 285, 22-30. [CrossRef]

47. Naseem, K.; Farooqi, Z.H.; Begum, R.; Ghufran, M.; Zia, M.; Rehman, U.; Najeeb, J.; Irfan, A.; Al-sehemi, A.G. Poly ( $\mathrm{N}$-isopropylmethacrylamide-acrylic acid) microgels as adsorbent for removal of toxic dyes from aqueous medium. J. Mol. Liquid. 2018, 268, 229-238. [CrossRef]

48. Mishra, A.K.; Agrawal, N.R.; Das, I. Synthesis of water dispersible dendritic amino acid modified polythiophenes as highly effective adsorbent for removal of methylene blue. J. Environ. Chem. Eng. 2017, 5, 4923-4936. [CrossRef]

49. Alqadami, A.A.; Naushad, M.; Alothman, Z.A.; Ahamad, T. Adsorptive performance of MOF nanocomposite for methylene blue and malachite green dyes: Kinetics, isotherm and mechanism. J. Environ. Manag. 2018, 223, 29-36. [CrossRef]

50. Asfaram, A.; Ghaedi, M.; Hossein, M.; Azqhandi, A.; Goudarzi, A.; Hajati, S. Ultrasound-assisted binary adsorption of dyes onto Mn @ CuS/ZnS-NC-AC as a novel adsorbent: Application of chemometrics for optimization and modeling. J. Ind. Eng. Chem. 2017, 54, 377-388. [CrossRef]

51. Idan, I.J.; Nurul, S.; Binti, A.; Abdullah, L.C.; Shean, T.; Choong, Y. Removal of Reactive Anionic Dyes from Binary Solutions by Adsorption onto Quaternized Kenaf Core Fiber. Int. J. Chem. Eng. 2017, 2017, 1-13. [CrossRef]

52. Regti, A.; Kassimi, A.E.; Laamari, M.R.; Haddad, M. El Competitive adsorption and optimization of binary mixture of textile dyes: A factorial design analysis. J. Ass. Arab Univ. Basic Appl. Sci. 2017, 24, 1-9.

53. Kurniawan, A.; Sutiono, H.; Indraswati, N.; Ismadji, S. Removal of basic dyes in binary system by adsorption using rarasaponin-bentonite: Revisited of extended Langmuir model. Chem. Eng. J. 2012, 189-190, $264-274$. [CrossRef]

54. Ziane, S.; Bessaha, F.; Marouf-khelifa, K.; Khelifa, A. Single and binary adsorption of reactive black 5 and Congo red on modi fi ed dolomite: Performance and mechanism. J. Mol. Liquid. 2018, 249, 1245-1253. [CrossRef]

55. Yang, S.; Wu, Y.; Aierken, A.; Zhang, M.; Fang, P.; Fan, Y. Mono/competitive adsorption of Arsenic (III) and Nickel (II) using modified green tea waste. J. Taiwan Inst. Chem. Eng. 2016, 60, 213-221. [CrossRef]

56. Remenárová, L.; Pipíška, M.; Horník, M.; Augustín, J. Biosorption of cationic dyes BY1, BY2 by moss Rhytidiadelphus squarrosus from binary solutions. Nova Biotechnol. 2009, 9, 239-247.

57. Noroozi, B.; Sorial, G.A. Applicable models for multi-component adsorption of dyes: A review. J. Environ. Sci. 2013, 25, 419-429. [CrossRef]

58. Mavinkattimath, R.G.; Kodialbail, V.S. Simultaneous adsorption of Remazol brilliant blue and Disperse orange dyes on red mud and isotherms for the mixed dye system. Environ. Sci. Pollut. Res. 2017, 24, 18912-18925. [CrossRef] [PubMed]

59. Ahmaruzzaman, M.; Reza, R.A. Decontamination of Cationic and Anionic Dyes in Single and Binary Mode From Aqueous Phase by Mesoporous Pulp Waste. Environ. Prog. Sust. Energy 2015, 34, 724-735. [CrossRef]

60. Hu, M.; Yan, X.; Hu, X.; Zhang, J.; Feng, R.; Zhou, M. Ultra-high adsorption capacity of MgO/SiO ${ }_{2}$ composites with rough surfaces for Congo red removal from water. J. Colloid Interf. Sci. 2018, 510, 111-117. [CrossRef]

61. Hameed, K.S.; Muthirulan, P.; Sundaram, M.M. Adsorption of chromotrope dye onto activated carbons obtained from the seeds of various plants: Equilibrium and kinetics studies. Arab J. Chem. 2017, 10, S2225-S2233. [CrossRef] 
62. Sekulic, M.T.; Boskovic, N.; Milanovic, M.; Grujic, N.; Gligoric, E.; Pap, S. An insight into the adsorption of three emerging pharmaceutical contaminants on multifunctional carbonous adsorbent: Mechanisms, modelling and metal coadsorption. J. Mol. Liquid. 2019, 284, 372-382. [CrossRef]

63. Lata, H.; Garg, V.K.; Gupta, R.K. Adsorptive removal of basic dye by chemically activated Parthenium biomass: Equilibrium and kinetic modeling. Desalination 2008, 219, 250-261. [CrossRef]

(C) 2019 by the authors. Licensee MDPI, Basel, Switzerland. This article is an open access article distributed under the terms and conditions of the Creative Commons Attribution (CC BY) license (http://creativecommons.org/licenses/by/4.0/). 